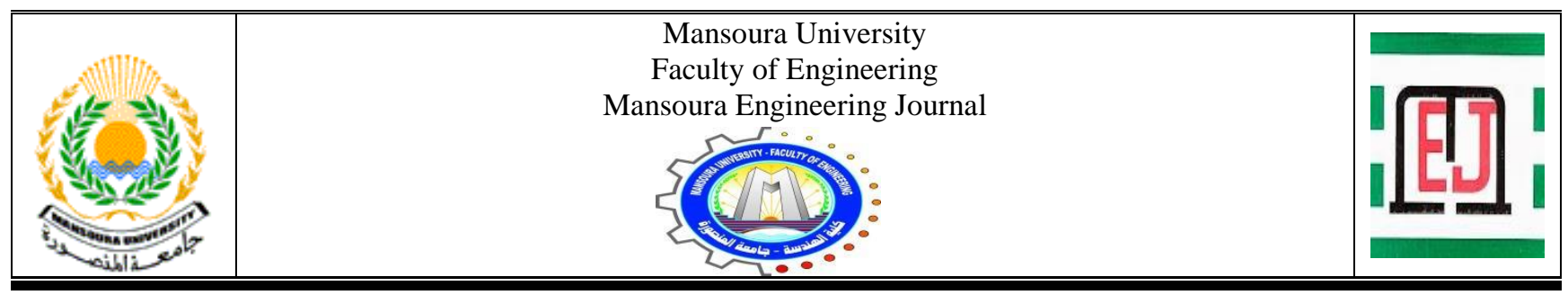

\title{
Development of Behavioral Treatment Centers to Reduce the Severity of Excess Motor Activity for Children with Hyperactivity Disorder
}

\begin{tabular}{|l|}
\hline KEYWORDS: \\
Solar radiation; \\
Thermal \\
facing $\quad$ materials; \\
Albedo; $\quad$ Reflection \\
coefficient; Absorption \\
factor; Heat protection; \\
Heat insulation \\
\end{tabular}

\author{
Shimaa Abd El-Majeed Ibrahim
}

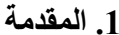

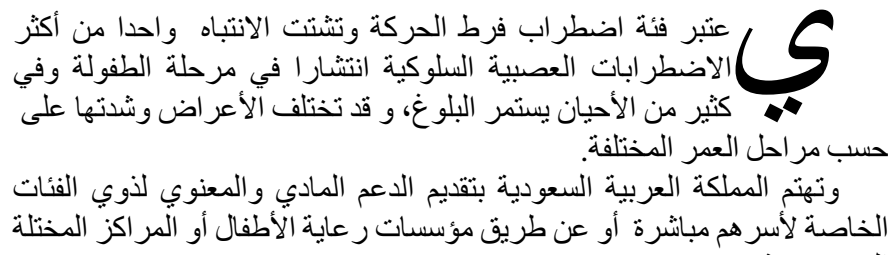

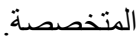

Received: (11 January, 2021) - Revised: (07 June, 2021) - Accepted: (08 June, 2021)

Corresponding Author: Dr. Shimaa Abd El-Majeed Ibrahim, Assistant Professor at El Gazeera Institute (EGI) Faculty of Engineering, Al-Mukattam, Egypt- https://eng.gi.edu.eg/(Mail: Shimaa.allam@ymail.com) 


\section{3. الجهات الرسمية الراعية لحقوق فرط الحركة / تثتت الانتباه}

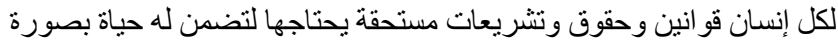

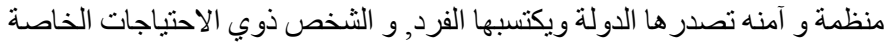

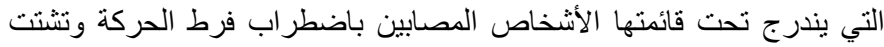

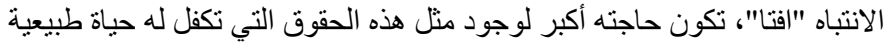

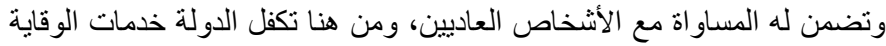

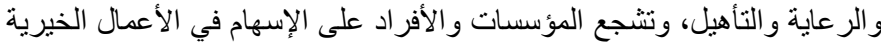

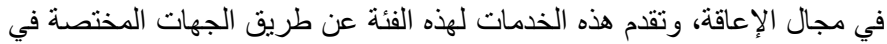

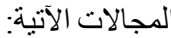

1-3 1-3 الدجالات الصحية: (4)

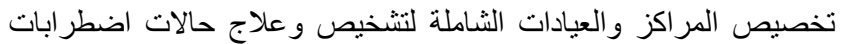
فرط الحركة /تشتت الانتباه، مع نوفير الكو ادر التنحصة التصني اللازمة لذلك .

2-3 المجالات التعليمية والتربوية (5)

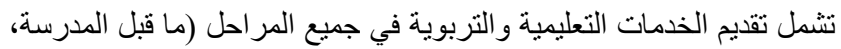

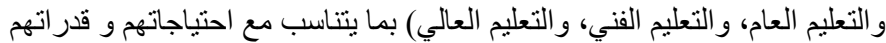

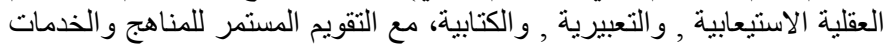

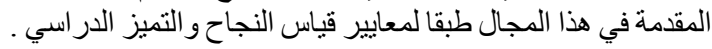

3-3 المجالات التندريبية والثأهيلية (4)

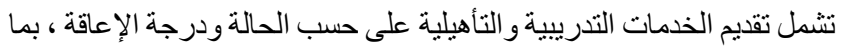

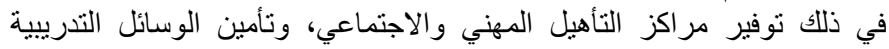
الملائمة لهم و بحسب ضوض ابط القبول المتبعة بتلاك المر اكز .

4-3 المراكز العلاجبة السلوكية:

عبارة عن مجموعة من الأنثطة و الجهود الكثيفة التي تبذلها الحكومات

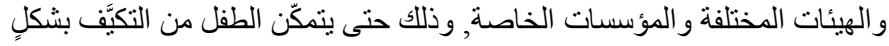

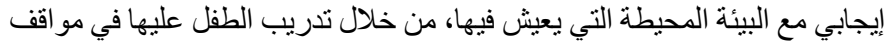

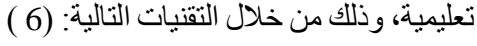

1-4-3 التعزيز : عبارة عن مكافئة الطفل إما: ماديا ببعض النقود، أو معنويا

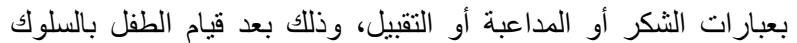
الصحيح الذي يترتب عليه. 2-4-3 الملاحظة والنمذجة: عبارة عن تعلم الطفل سلوك جديد بعد الملاحظة ومتابعة الاداء بو اسطة أشخاص آخرين.

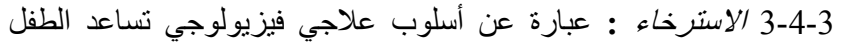

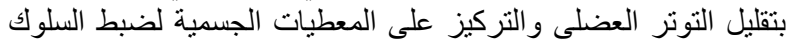
الاندفاعي الحادث لديهم . 4-4-3 ضبط الذات : عبارة عن تقييم وتعزيز الضبط الذاتي تدريجيا عبر التبر

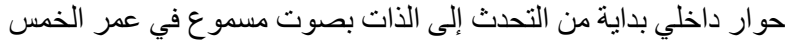

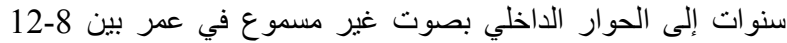

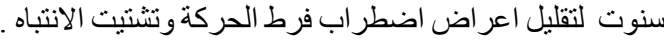

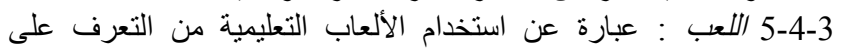

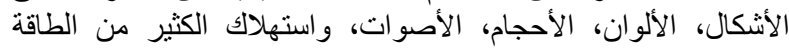

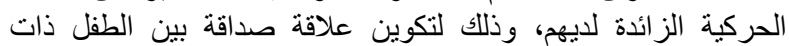

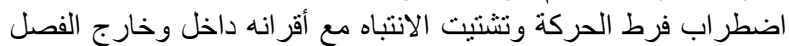
الدراسي لتعبير عن مشاعره وأحاسيسه و أفكاره ور غباتها

\section{4. الاعتبارات والمتطلبات التصميمية الداخلية للمر اكز العلاجية والسلوكية}

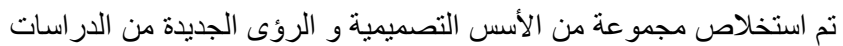

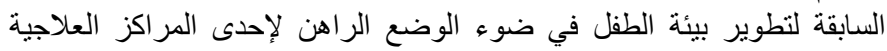

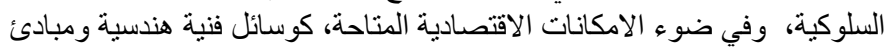
إرشادية ، للعمل بها في تصميم المر اكز العلاجية والسلوكية، فهي كالتالي:
وتـأتي المثكلة البحثية : في عدم الو عي الكسافي في المجتمع وبين الأهل

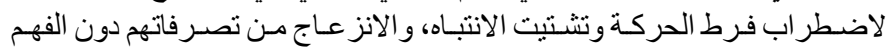

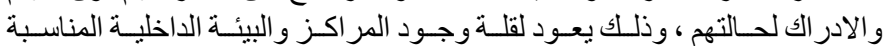

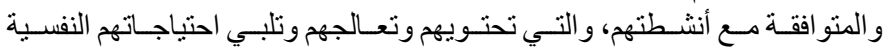

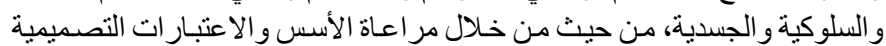

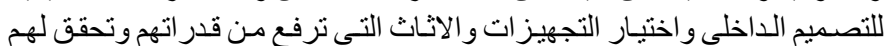

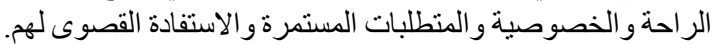

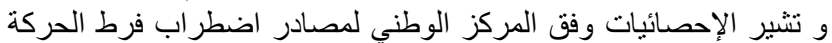

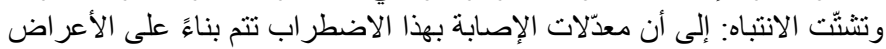

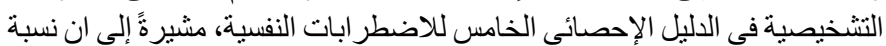

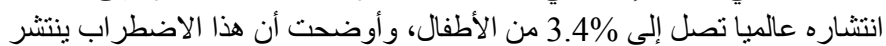

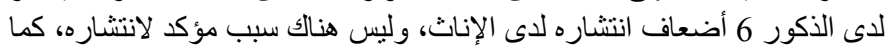

يتّضح أكثر في عمر دخول المدرسة.

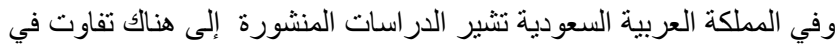

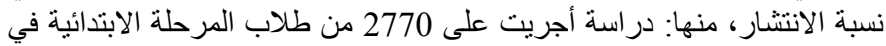

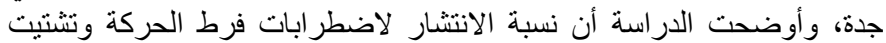

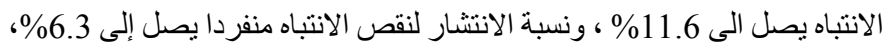

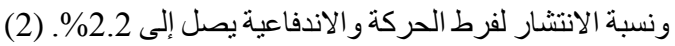

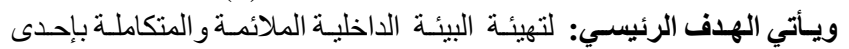

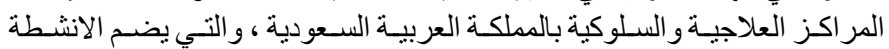

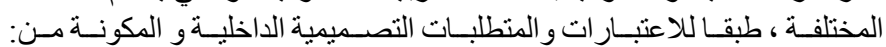

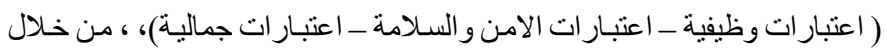

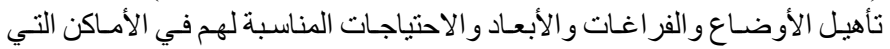

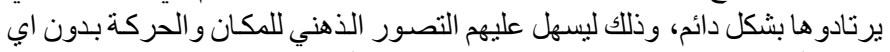

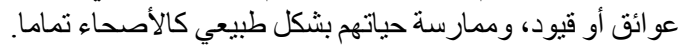

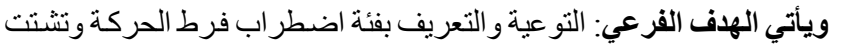

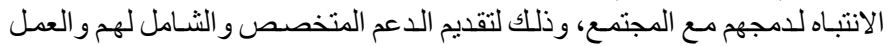
على ضمان حقو قهم. و ينقسم البحث لتحقيق أهدافه على المناهج الرئيسية التالية:

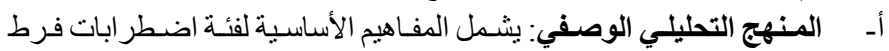

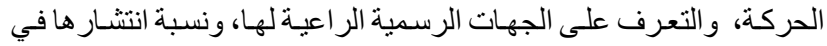

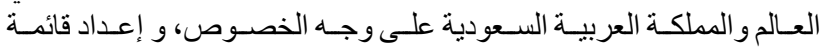

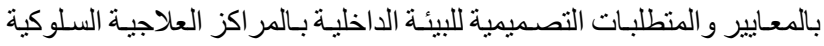

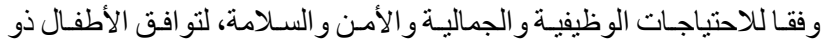
اضطر ابات فرط الحركة وتثتيت الالتنباه

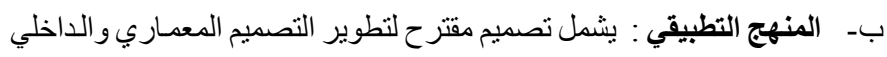

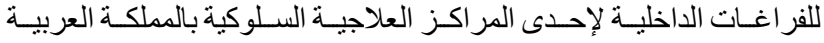

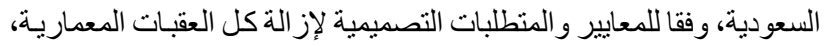

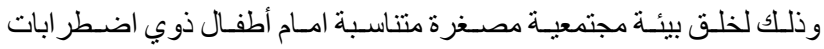

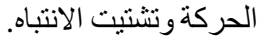

\section{2. تعاريف ومفاهيم عسامة لإضر اب فرط الحركة / تثتت الانتباه}

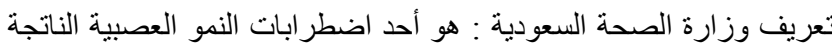

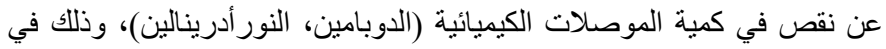

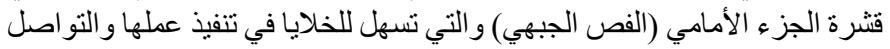

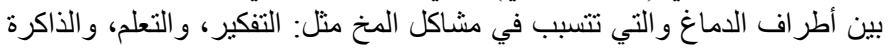

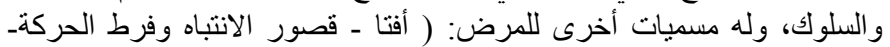

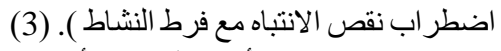

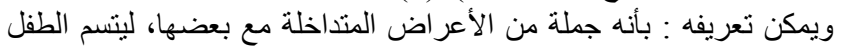

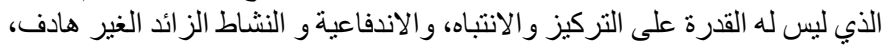

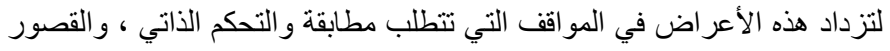

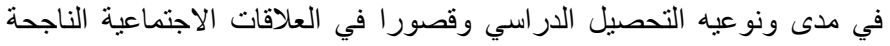
(مجدي عبد الله، 2005م ). 


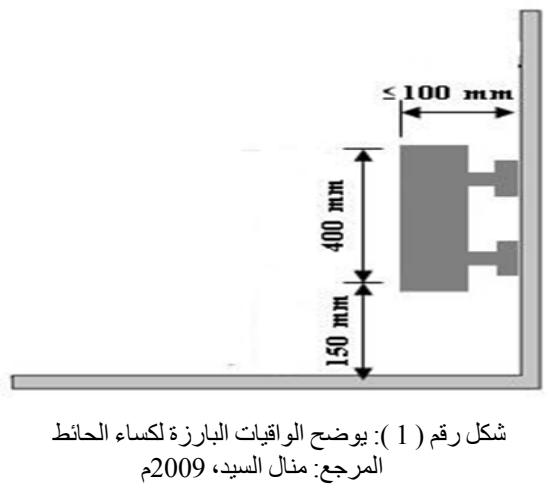

في حالة استعمال و اقيات من الارنطام ( الصدمات) لتحمي الجدار من الخدوش

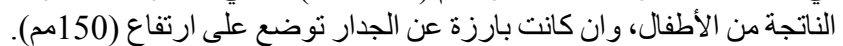

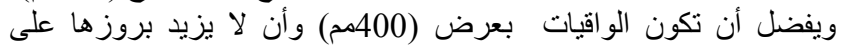

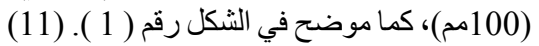

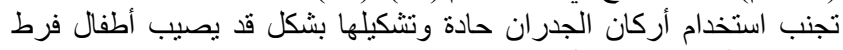

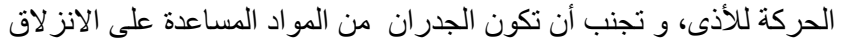

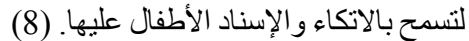

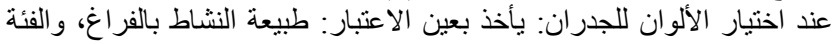

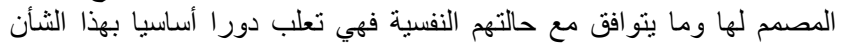

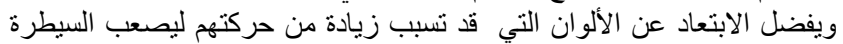

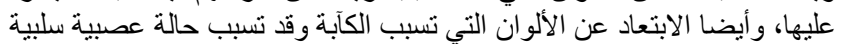

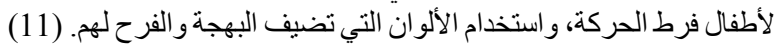

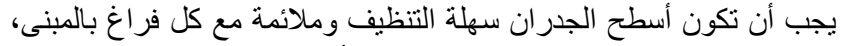

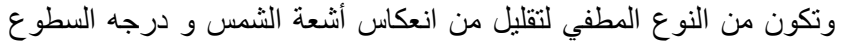

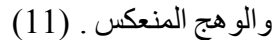

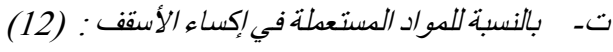
عدم إظهار شكل المواسير والتوصيلات في أسقف الفراء الاتعات لما لها من آثر

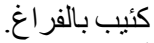

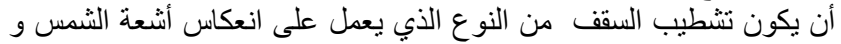

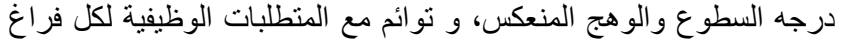

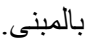

2-4 2 اعتبارات الأمن والسلامة: (7)

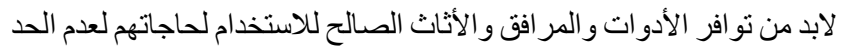

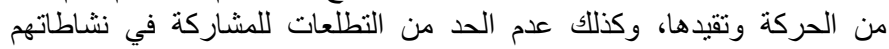
المجتمعية، ويأتي ذللك من خلال: المناك استخدام عناصر الفرش الداخلية والألعاب المناسبة لسن الطفل. تحقيق مرونة التصميم ليتمانشى مع التغييرات الاحتياجية و الفسيولوجية التئي

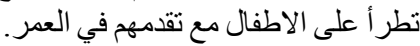

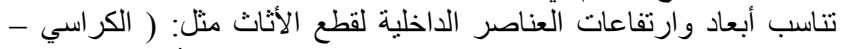

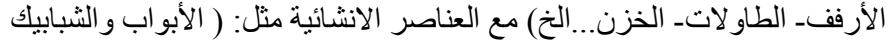
و الممرات و المنحدر ات ومفاتيح الإضـاءة و الكهرباء... الخ).

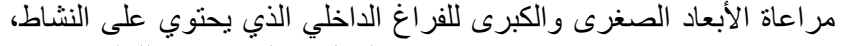

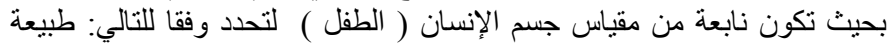

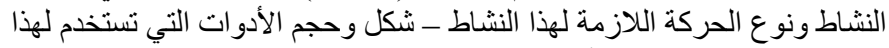

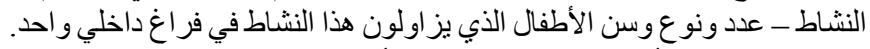

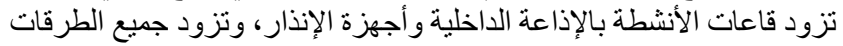

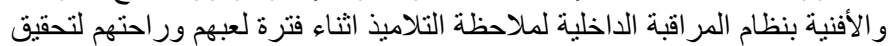

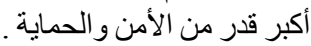
يجب أن لا تكون مفاتيح الكهرباء و الإضاءة بمتناول أيدي الأطفال فرط الحركة بحيث يفضل وضع المفاتيح بعيده عن متناول أيديهم.
1-1-4 تصميم الفراغات الداخلية : يتم مر اعات الفراغات الحميمة لدى الدير

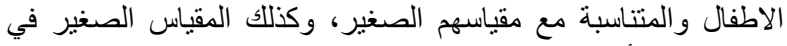

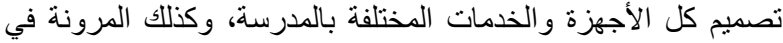

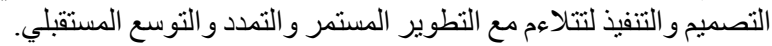

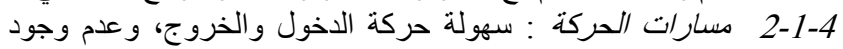

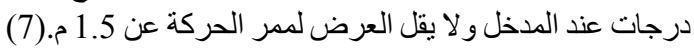
يجب تصميم جميع الاسطح المائلة او المنحدرة لتوفر الحركة الحركة الآمنة، وخاصها

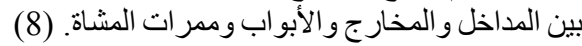

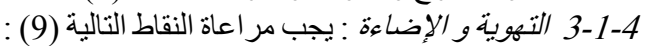

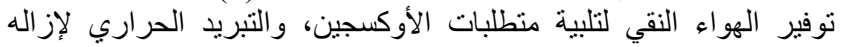

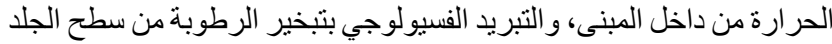

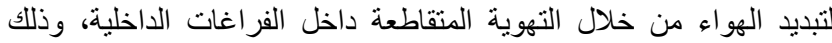

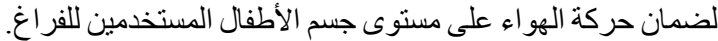

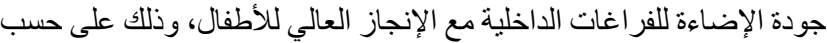

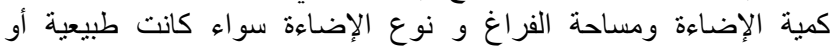

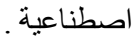

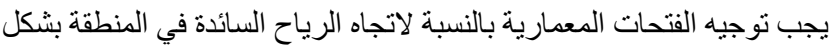

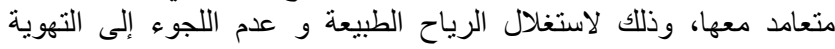

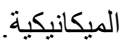

استخدام الفتحات المعمارية على مستوى منخفض للاستفادة من الهواء البارد و وعلى مستوى عالي لاستخر اج الهو اء الأكثر دفئًا.

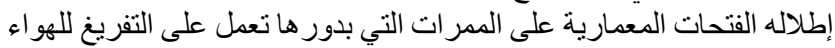

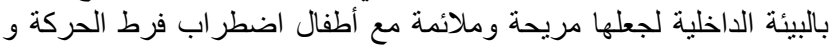
تنتيت الانتباه. 4-1-4 مواد النهو (التثطييات ) : يجب تناسب الأبعاد وارتفاعات العناصر

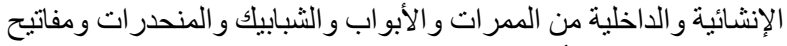

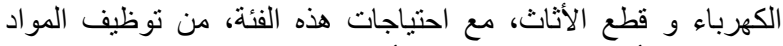
المستعملة بالأرضيات و الجدران و الأسقق كالتالي:

$$
\text { أ- بالنسبة للمواد المستعهلة في إكساء الأرضيات : (10) }
$$

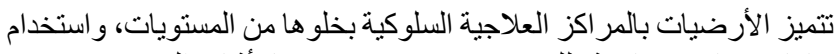

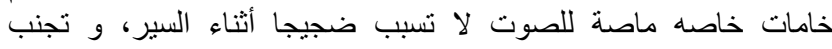
الأرضيات اللامعة والمصقولة والملساء، ومن أهم و أكثر المواد المستخدمة

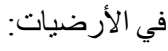

\section{• السجاد}

يتميز بأنه مادة مانعة للانز لاق ويخفف من حدة الصدمات عند سقوط أطفال

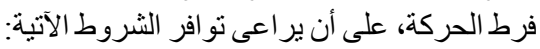

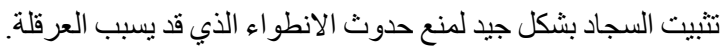

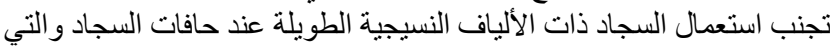

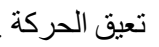

البلاط جئ

يشمل جميع أنو اع البلاط الصلب الغير قابل للتثبوه اللان مثل: الرخام والموز اييك

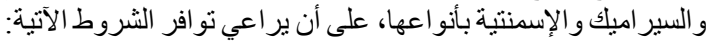

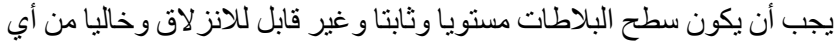

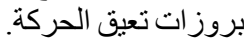

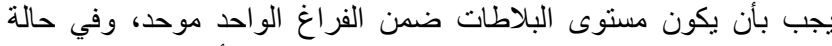

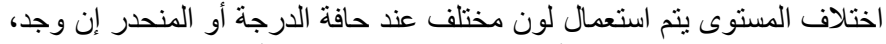

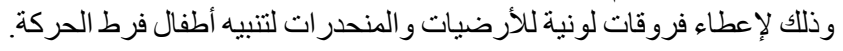

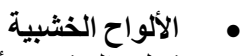

يشمل الخشب بأنواعه المختلفة: الطري و القاسي والمصنع في إكساء الأرضيات، على أن ير اعي تو افر الثروط الثر الآتية:

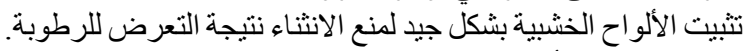

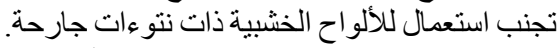
تجنب التعرض للرطوبة والحر ارة العالية للألو اح الخشبية. 
4-5 الإيجابيات والسلبيات لجمعية /إشراق :

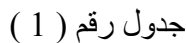

يوضح الإيجابيات و السلبيات لجمعية إنشراق

المصدر : مقابلات شخصية مع المختصين المين

\begin{tabular}{|c|c|}
\hline السلبيات & الإيجابيات \\
\hline 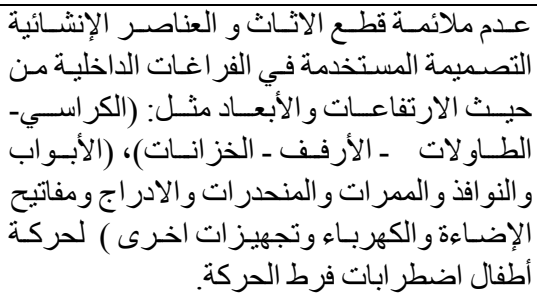 & 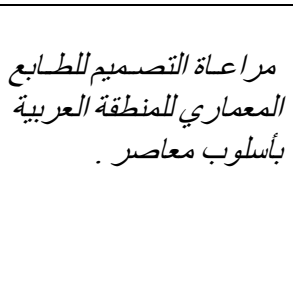 \\
\hline 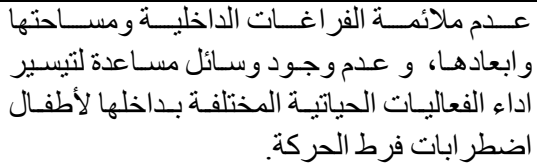 & 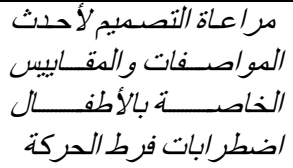 \\
\hline 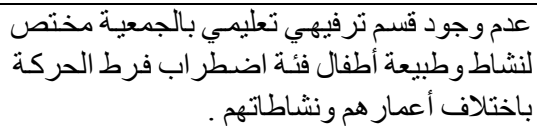 & 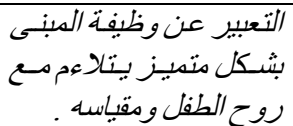 \\
\hline 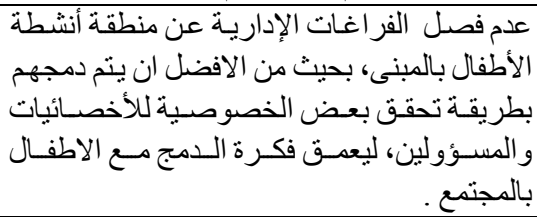 & 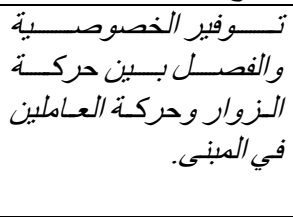 \\
\hline
\end{tabular}

5-5 مكونات واقسام فراغات الجمعية للبيئة الداخلية لفئة اضطر اب فرط الحركة

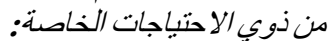

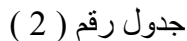

يوضح مكونات الفر اغات الوظيفية لجمعية إثراق

\begin{tabular}{|c|c|c|}
\hline قسم إداري & قسم تعليمي & 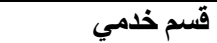 \\
\hline 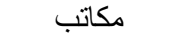 & الفصول & المدخل الرئيسي \\
\hline علاقات عامة & التعليمية & الاستقبال و الانتظار \\
\hline قاعة اجتماعات & المكتبة & دور ات المياه \\
\hline
\end{tabular}

6-5 تحليل الوضع الر اهن للمساقط الأفقية من حيث الفراغات الوظبفة بالجمعية :

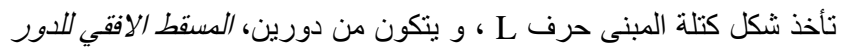
الأرضي ذات المساحة الكلية للمسقط 393متر مربع، كما هو موضح بلى بالثكل رقم

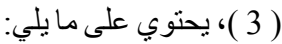

منطقة المدخل الرئيسي والاستقبال : هي منطقة هامة انتقالية من شدة الإضاءة الخاءة الخارجية إلى الضوء الداخلي الخافت، ليضم مكتب الاستقبال ومنطقة استقبال أولياء

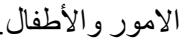
منطقة الانتظار: هي صالة كبيرة لانتظار أولياء الأمور و الأطفال في توقيتهم

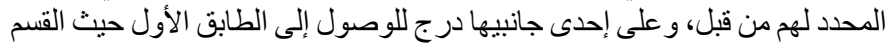

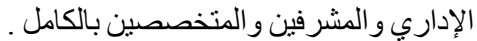

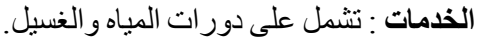

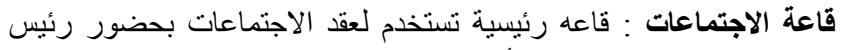

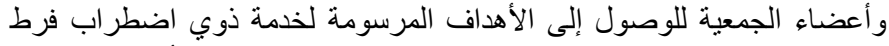

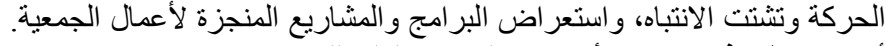

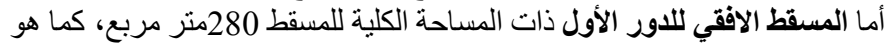

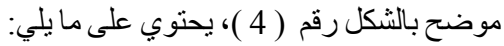
الإدارة : تشمل على: شؤون الموظفين، الدحاسبين، المدير، السكرتارية،

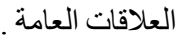

ويفضل استخدام أجهزة التحكم عن بعد ( الريموت كونترول ) للإضـاءة وأجهزة التكييف والأجززة الكهربائية لعدم عبث الاطفال فيها. 3-4 الوعتبارات الجمالية:

بالرغم من تثكيل المبنى كوحدة معمارية واحدة الا ان تشكيل التهيل الواجهة

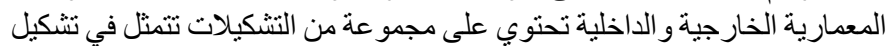

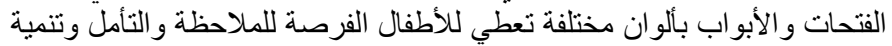

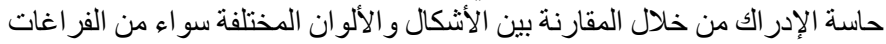

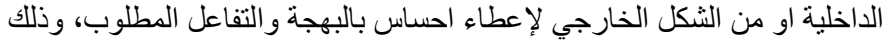
التعبر الفراغات وشكلها عن وظيفتها لتعكس الصورة الذاع الذهنية إليها، وذللك من خلال:

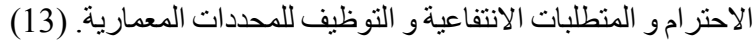

\section{5. دراسة وتحليل للوضع الراهن للمر اكز العلاجية والسلوكية (جمعية إثراق)} بالمملكة العربية السعودية_ وفقا للاعتبارات والمنطلبات التصاتية التصميمية

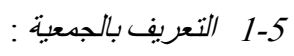

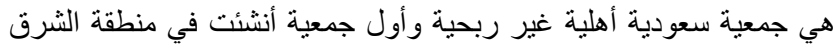

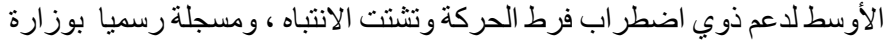

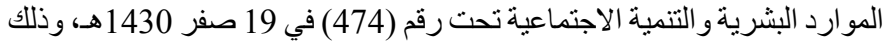

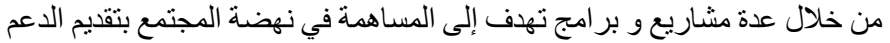

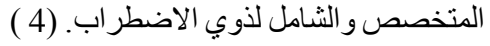

$$
\text { 2-5 اهداف الجمعية: (4) }
$$

نثر الو عي بين الأسر و أفر اد المجتمع وبين العاملين في الميدان مثل (الأطباءالتربويين_الأخصائيين النفسيين -الاجتماعيين.. وغير هم) و الطرق السليمة للتعامل مع الأطفال المصابين بأفتا.

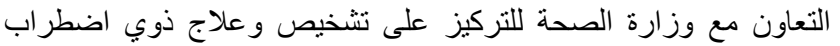

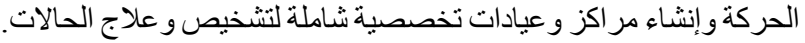

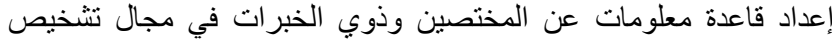
و علاج ذوي اضطر اب الحركة وتدريب الكو ادر البشرية بالجهات المعنية.

3-5 الدوقع الجنر/في للجمعية: تقع الجمعية في الملكة العربية السعودية - منطقة الرياض- حي السفاراتساحة الكندي شار ع عبدالله السهيمي.

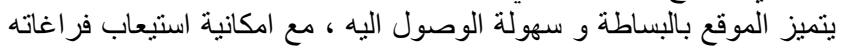

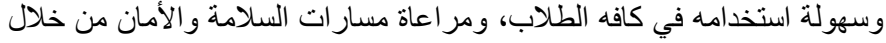

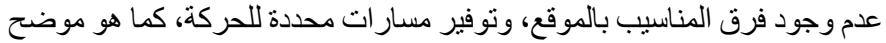

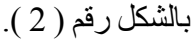

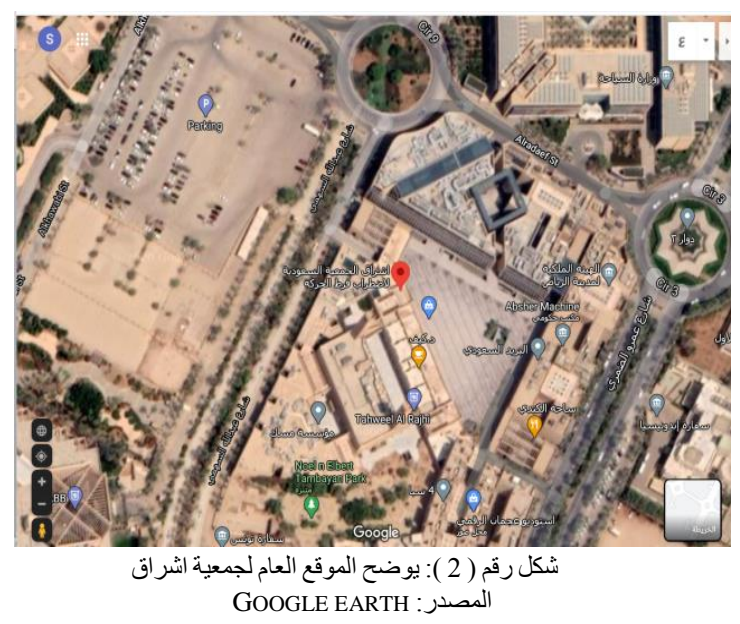




$$
\begin{aligned}
& \text { قاعة اجتماعات : قاعه ثانوية بالقرب من مكتب المدير و المكاتب الادارية المدخل للاور الأرضي. }
\end{aligned}
$$

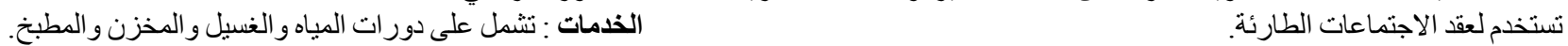
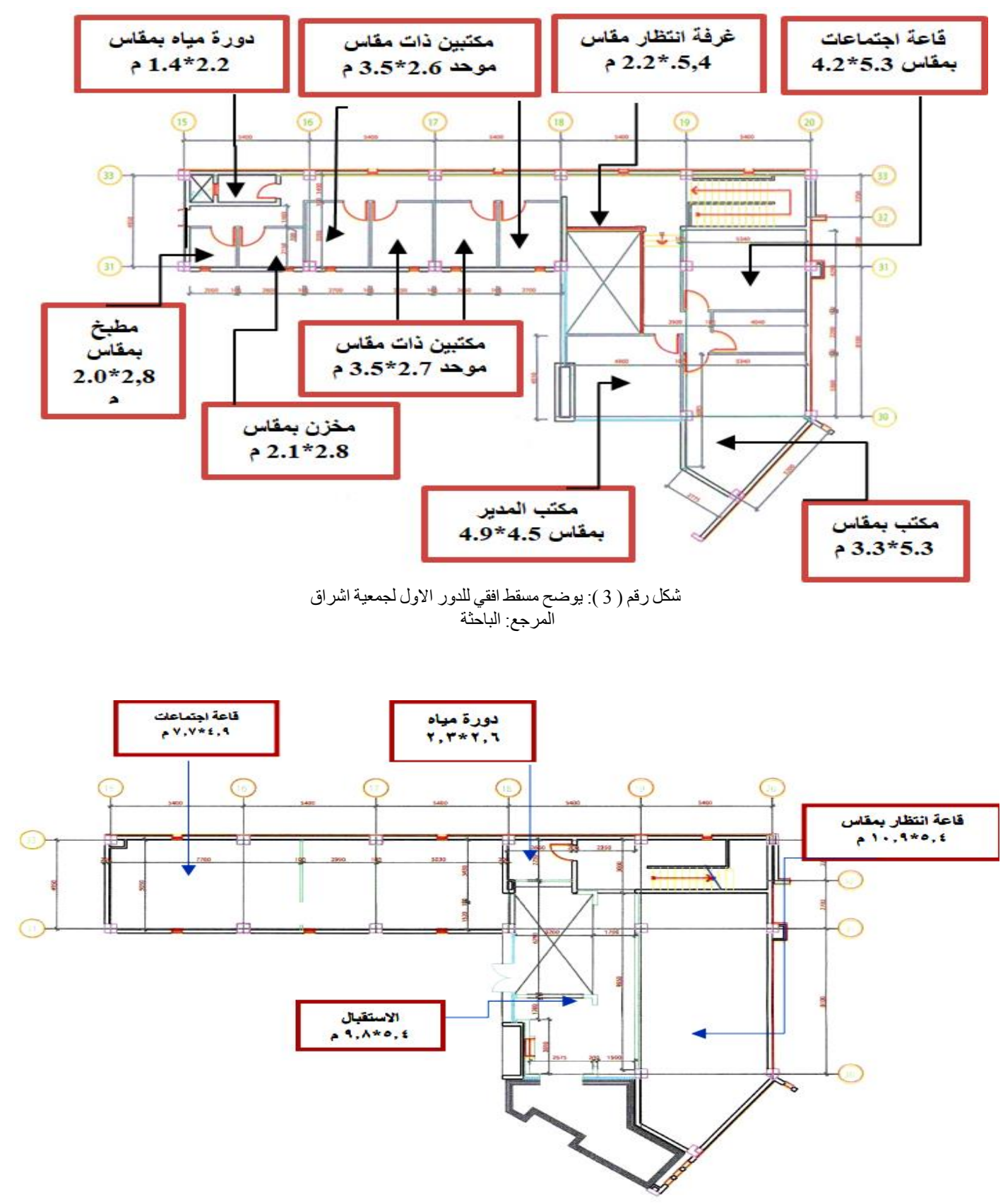

$$
\text { شكل رقم ( } 4 \text { ): يوضح مسقط الفقي للدور الأرضي لجمعية اشراق }
$$

و السير، و الأثاث المستخدم يلائم هذه الفئة حيث أن المقاعد منفصلة عن الطـاو لات،

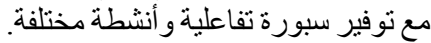

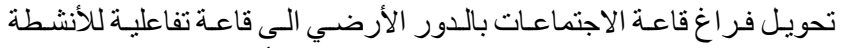
لأطفال فرط الحركة والاكتفاء بغرفة الاجتماعات الات بالدور الأول، بحيث يكون مدخلها تطوير فر اغ الاستقبال بشكل بسيط و عصري الأبر و جذاب، بحيث يتناسب لاستقبال الأطفال وأولياء الأمور داخل الأبمعية.

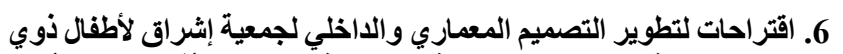

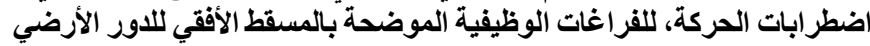

كما بالشكل التالي رقم ( 5 ) :

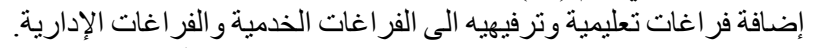

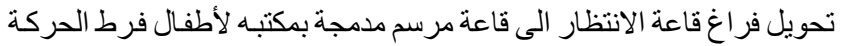

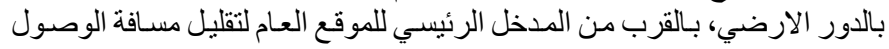




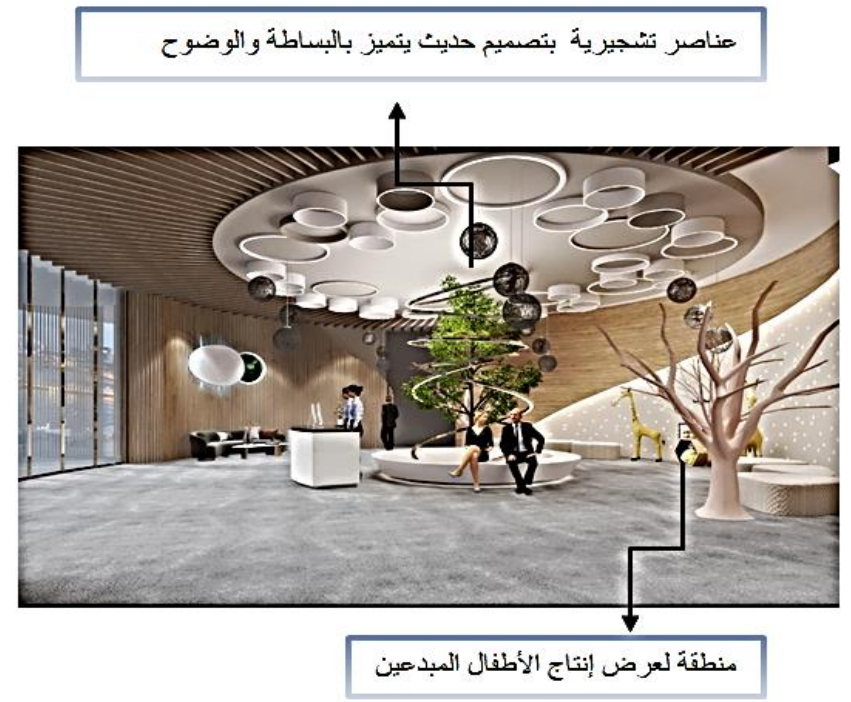

شكل رقم ( 6 ): يوضح فر اغ الاستقبال و العناصر التثجيرية و الزينية بتصميم عصري يبين نوعية الخدمة المقدمة في المكان ـ المرجع: الباحثة

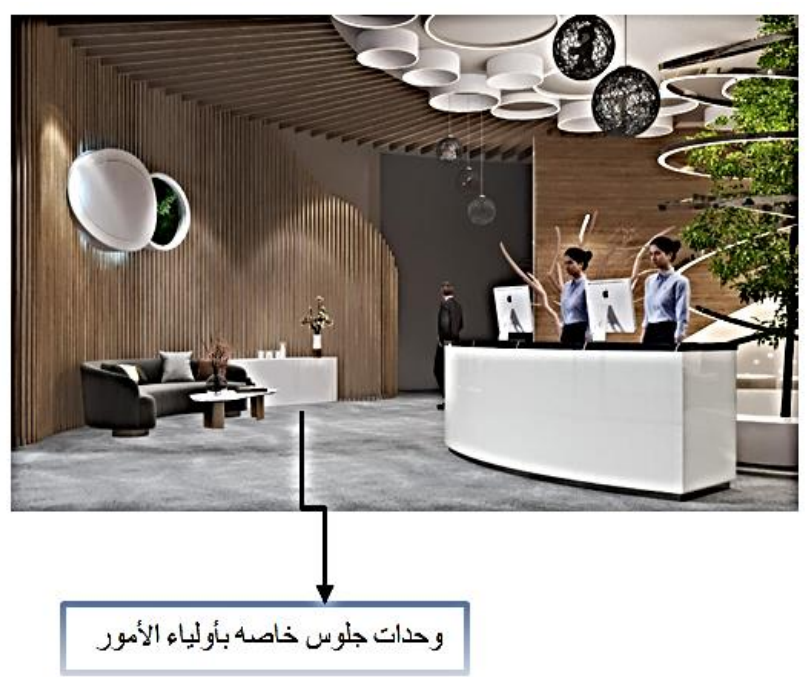

شكل رقم (7 ): يوضح مكتب الاستعلامات بتصميم عصري وجذاب بفر اغ الاستقبال : الإنة

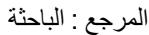

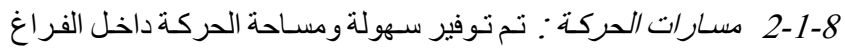

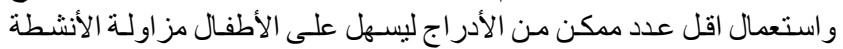
المختلفة فيه بكل راحة وسهولة وسلاسة .

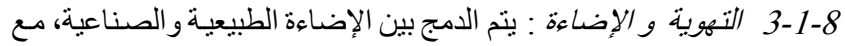

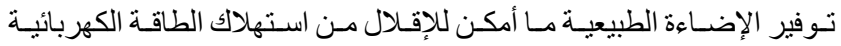

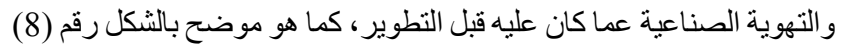

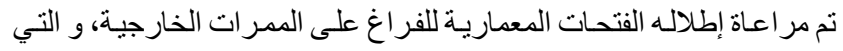

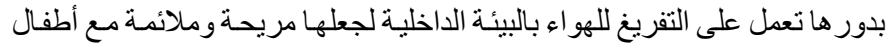
اضطر اب فرط الحركة و نشتيت الانتباه.

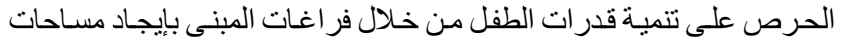

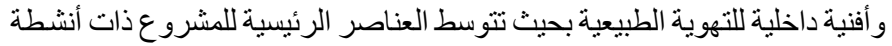
و ألو ان متميزة تجذب الطفل إليها.

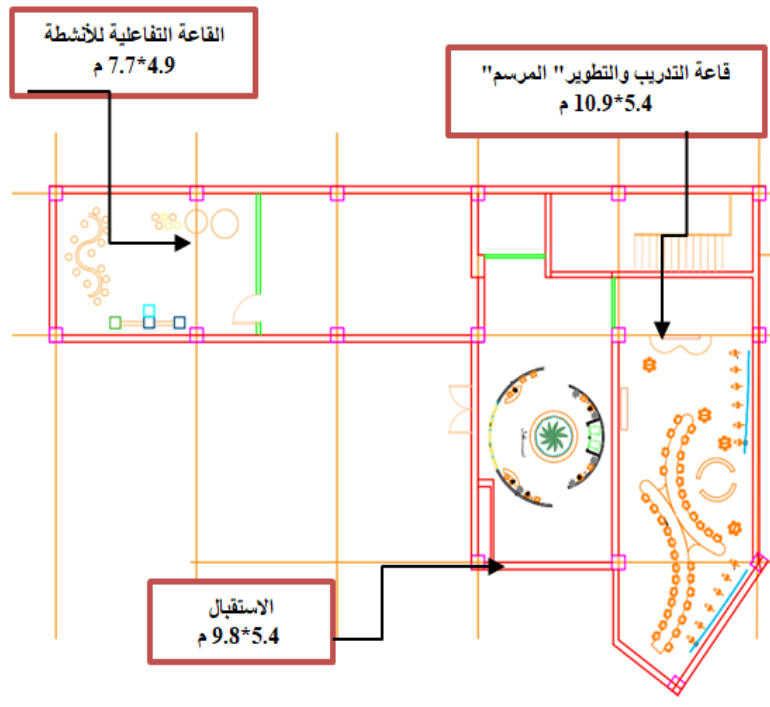

شكل رقم ( 5 ): : يوضح مسقط أفقي مقتر حللاور الأرضي لجمعية اشر اق الباق

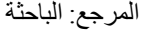

7. فلسفة التطوير للمسقط الأفقي للاور الأرضي

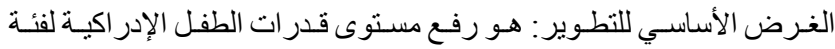

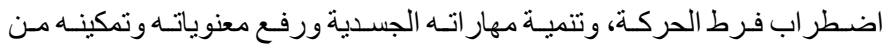

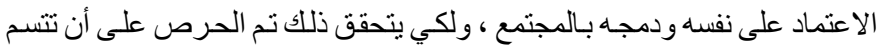

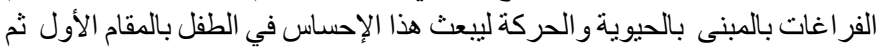

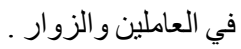

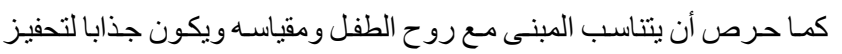

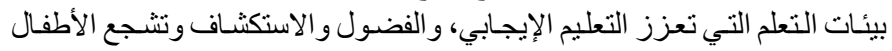

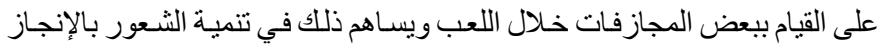

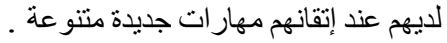

8. الاعتبارات و المتطلبات التصميمية للفراغ الأول ( الاستقبال ) بالجمعية

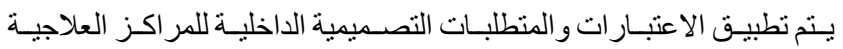
و السلوكية والتي تم شرحها في نقطة رقم (4) على جمعية إنثر اق، كالتالي:

1-8

1-1-8

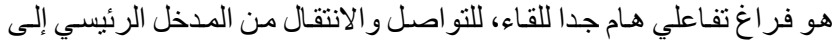

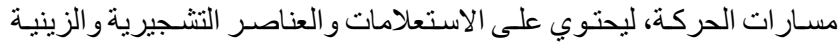

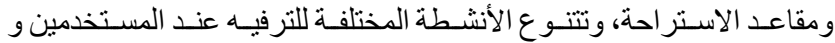

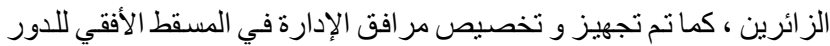
الأول للخصوصية ولنو كئر فير فرص وظيفية أكثر بالجمعية .

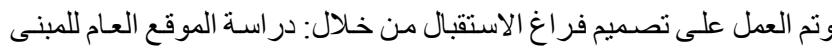

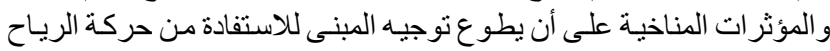

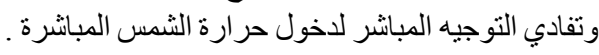

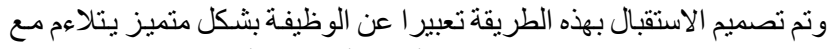

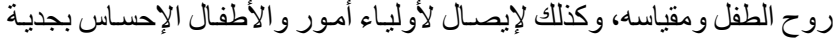

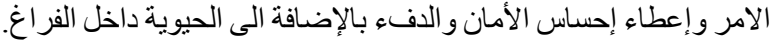


ل عمم فر اغ الاستقبال بمساحة كافيـة لتستو عب أكثر عدد من أوليـاء الأمور

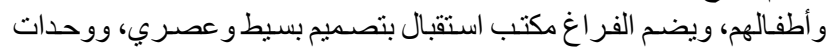

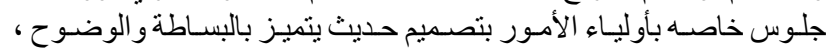

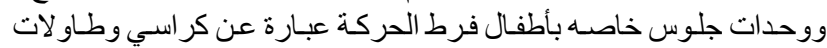

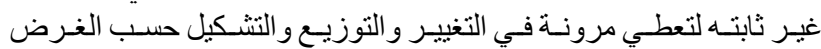
المطلوب، و عناصر تشجيرية وزينية لإضافة الطابع الجمالي داخل الفراغ.

$$
\text { 3-8 }
$$

نلاحظ استخدام عناصر معمارية تتسجم مع البيئة المحلية في الفتحات والأثاث

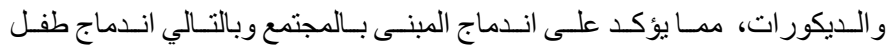
اضطر اب فرط الحركة مع المجتمع، كما بالأشكال رقم (11، 110).

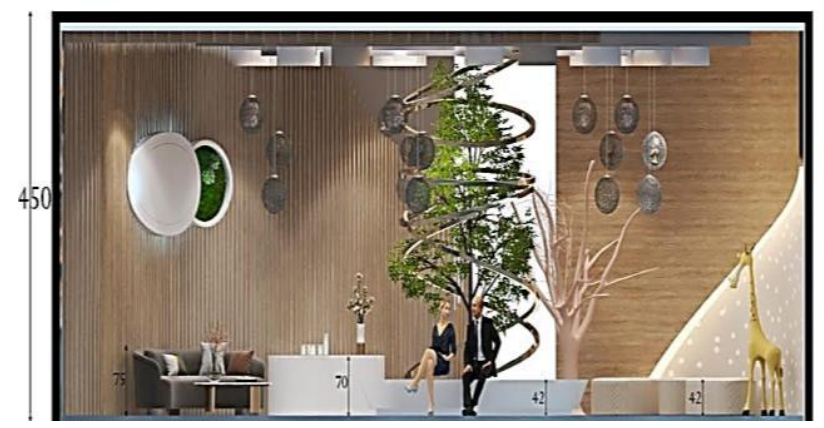

شكل رقم ( 10 ): يوضح التصميم الداخلي بالقطاع الر أسي لفر اغ الاستقبال

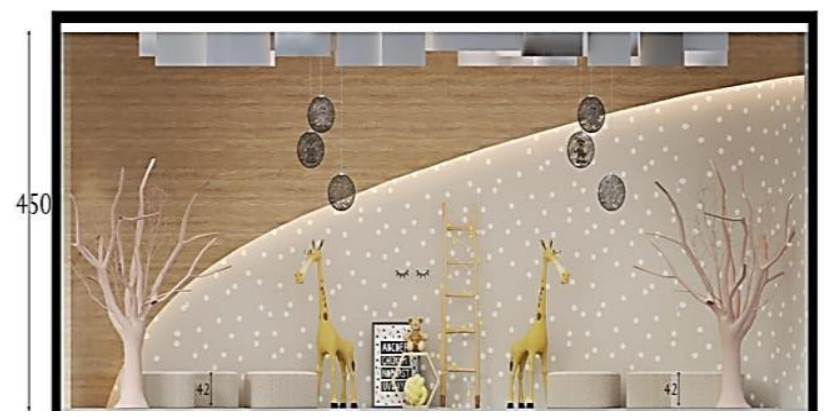

شكل رقم ( 11 ): يوضح التصميم الداخلي بالقطاع الأفقي لفر اغ الاستقبال

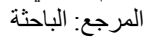

9. الاعتبارات والمتطلبات التصميمية للفراغ الثاني ( قاعة التدريب والتطوير

1-9 الاعتبارات الوظبفية :

1-1-9 تصمبم الفر اغات الداخلية:

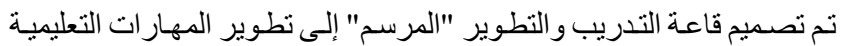
بطريقة ترفيهية إبداعية مـع بعض الأنشطة والمنـاطق المختلفة: منطقة أعمال

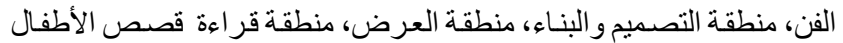

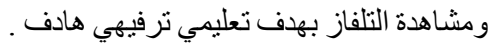

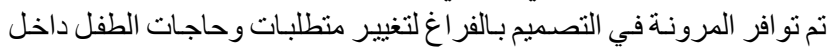

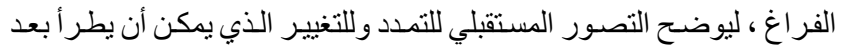
عملية التنفيذ الكلي او الجزئي للمكان، كما هو بالأشكال رقم ( 12،13 ).

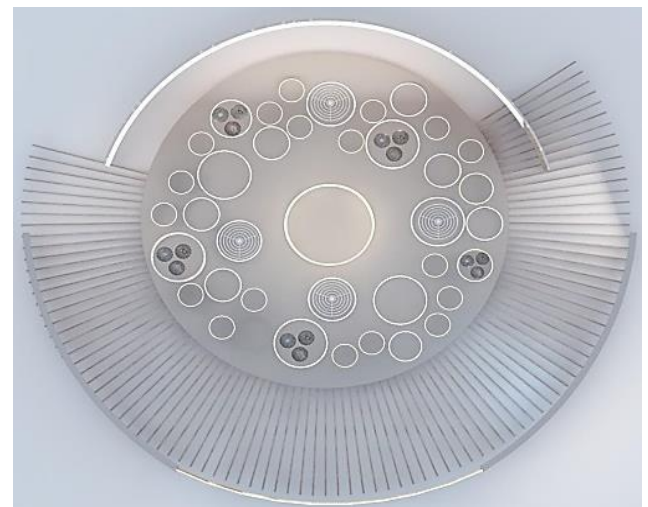

شكل رقم ( 8 ): : يوضح المسقط الأفقي لسقف فراغ الاستقبال

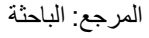

$$
\text { 4-1-8 مواد النهو (التشطبيات ) من حيث: }
$$

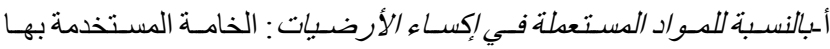

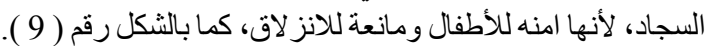

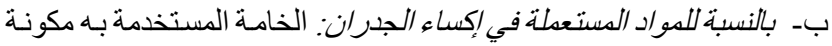

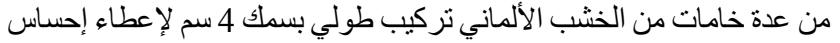
الدفه، وكذلك ورق الحائط لإضافة الحيوية و الابتعاد عن الأركان الحادة حتى لإكى لا يتعرض الطفل للأذى.

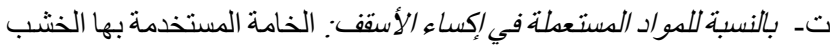

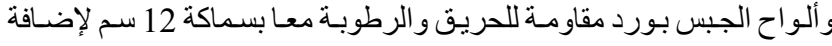

لمسه جمالية بالفر اغ.

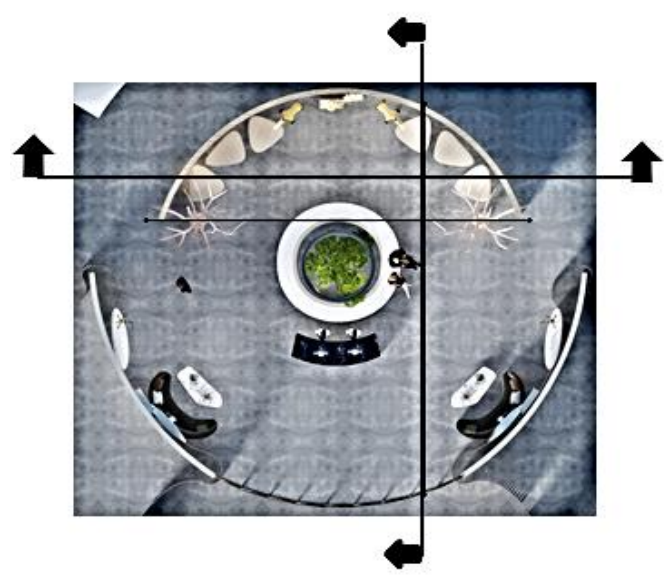

$$
\text { شكل رقم ( } 9 \text { ): يوضح المسقط الأفقي لفراغ الاستقبال }
$$

$$
\text { 2-8 }
$$

الابتعاد عن اختلاف المستو يات في الارضيات، واستخدام خامات من الطبيعة

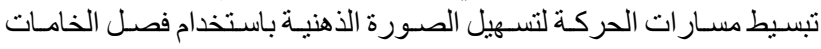
المختلفة لمسار ات الحركة.

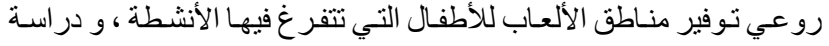

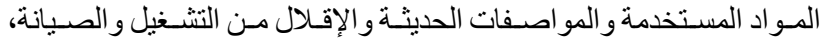
و العمل على توفير الطاقة ليتم التوصل إلى تنفيذ مبنى ذو كفاءة اقتصات التصادية عالية يحقق الاستفادة القصوى للاحتياجات المرجوة منه. 


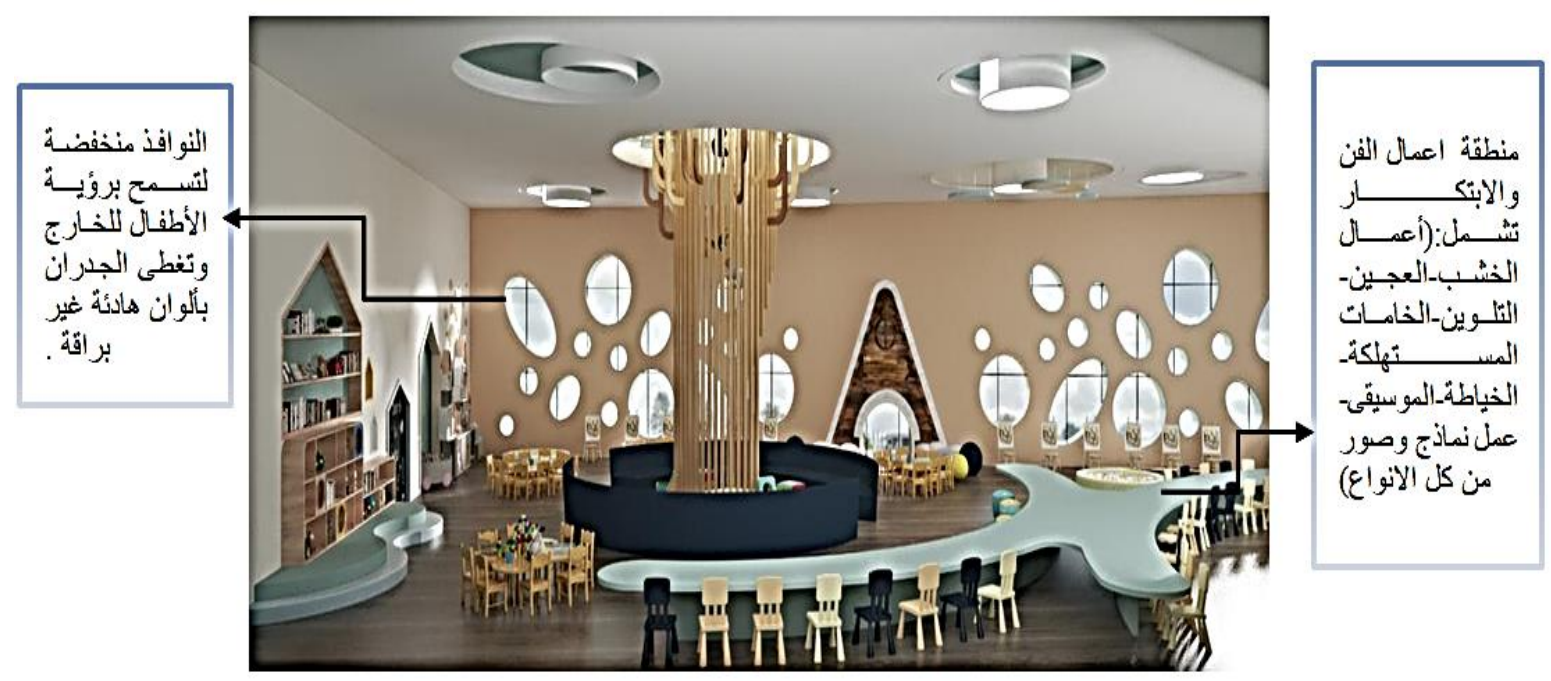

شكل رقم ( 12 ): بوضح فر اغ المرسم يحتوي على جميع الأدوات و التجهيز ات المناسبة في الحجم المناسب للأطفال

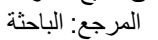

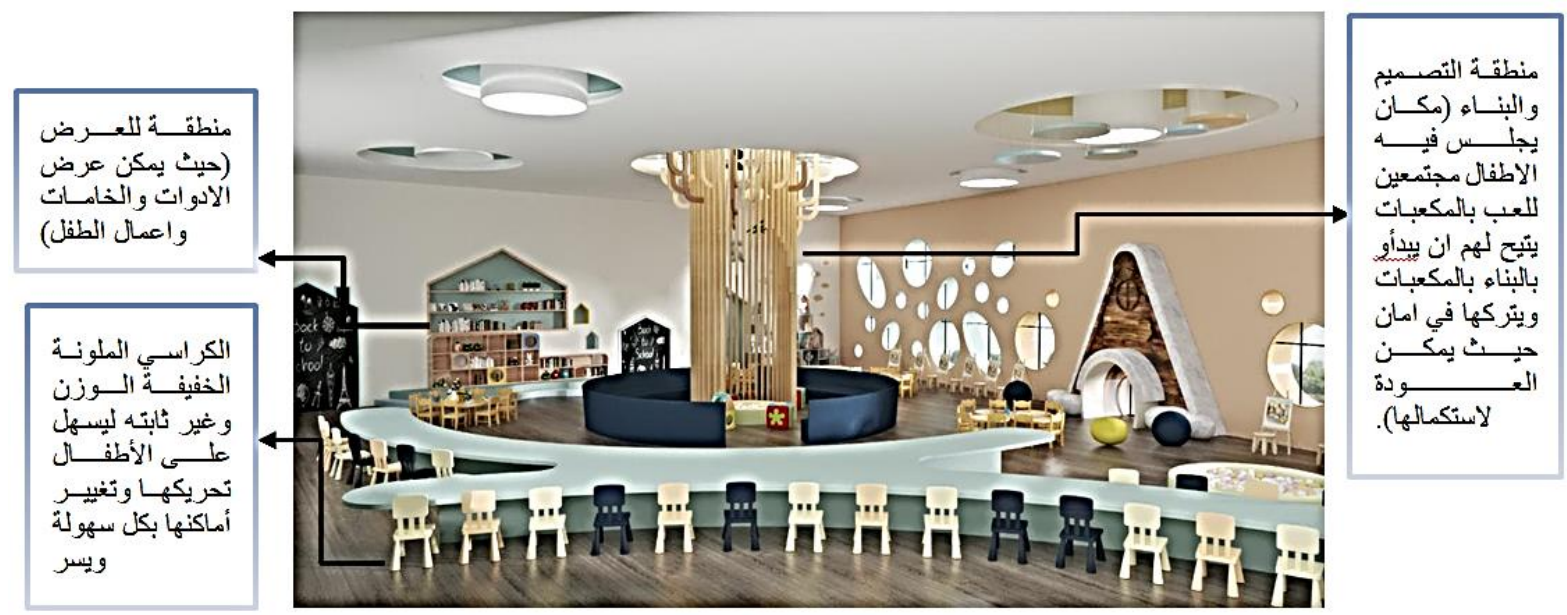

شكل رقم ( 13 ): يوضح نوفير الإضـاءة الطبيعية من خلال النو افذ المختلفة الدوائر والأحجام داخل المرسم

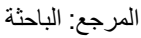

3-1-9 التهوية و الإضـاءة : تم التنوع بالنو افذ في مقاسات وأحجام الدو ائر و المواد

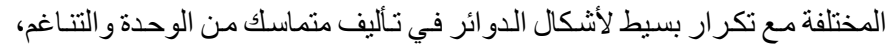

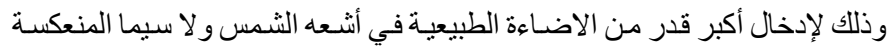

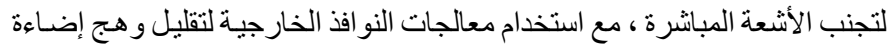

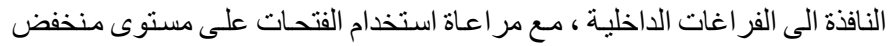

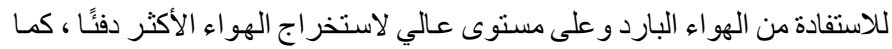

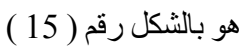

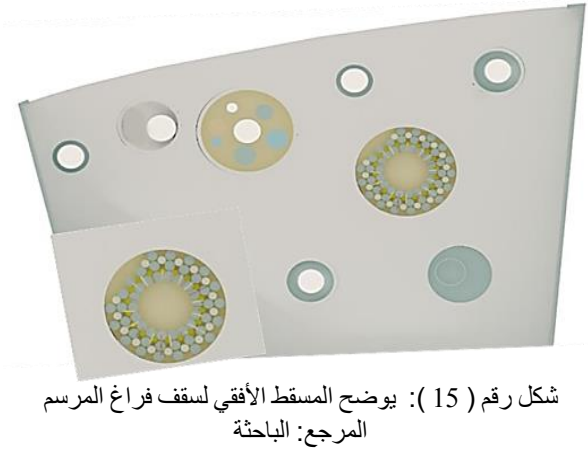

2-1-9 مسار ات الحركة : تم خلق امكانية الحركة لاستخدام اوسع في المسـاحات

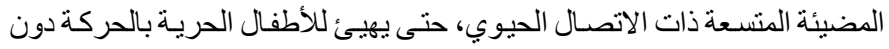

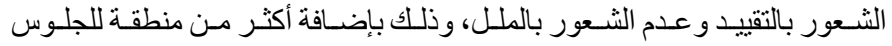
وللقر اءة و الرسم وبعض الألعاب الأمنه و الأنشطة المتعددة، كما بالثكل رقم (باضل

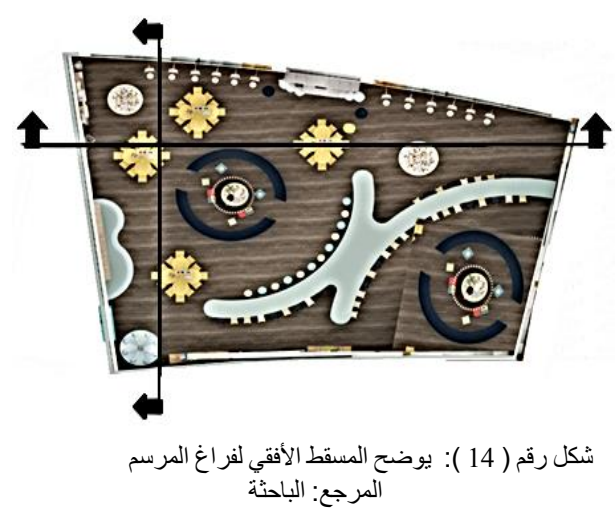




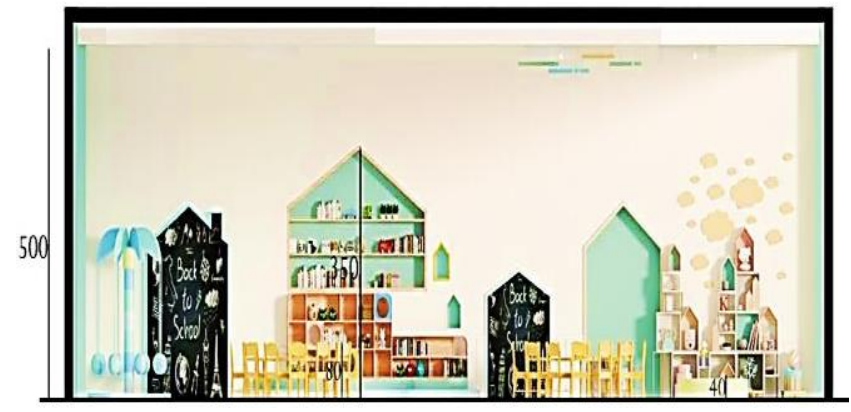

شكل رقم ( 16 ): يوضح التصميم الداخلي بالقطاع الرأسي لفر اغ المرسم المرجع: الباحثة

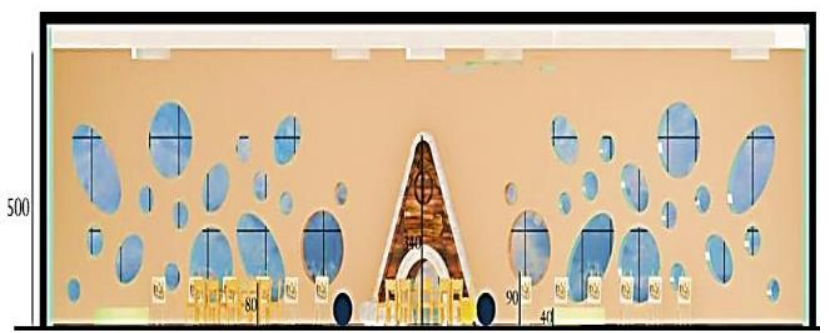

شكل رقم ( 17 ): يوضح التصميم: الداخلي بالقطاع الافقي لفر اغ المرسم

10. الاعتبارات والمتطلبات التصميمية للفراغ الثالث ( القاعة التفاعلية للأنثطة ) بالجمعية

1-10 الاعتبار ات الوظبفية:

1-1-10 تصميم الفراغات الداخلية:

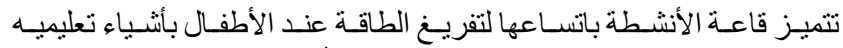

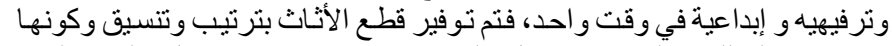

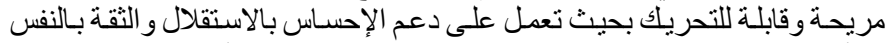

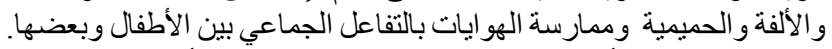

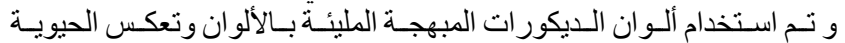

و المرح، لجذب الأطفال ولفت انتباههم، وتفريغ طاقتهم، وتغيير حالتهم النفسية، كما هو بالأشكال رقم ( 19،18 (19) ).
مواد النهو (التشطبيات ) من حيث:

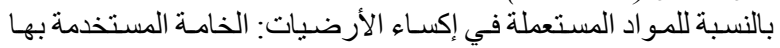

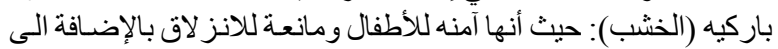

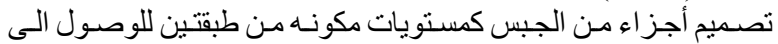
رفوف التخزين.

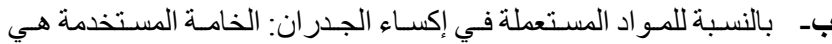

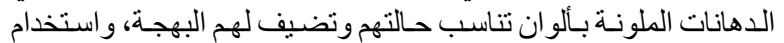

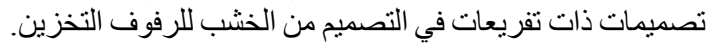

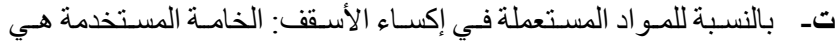

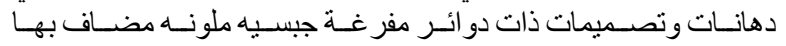

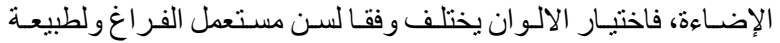

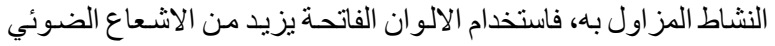

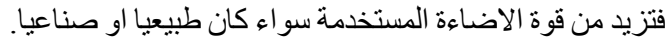

2-9 اعتبارات الأمن والسلامة:

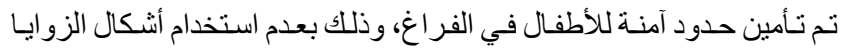

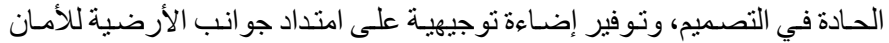

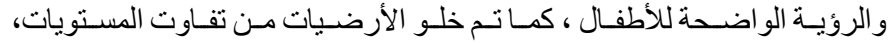

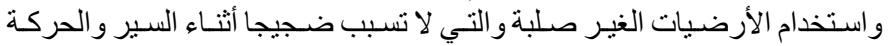
بالفر اغ. تم ملاءمة الأثاث المستخدم في التأثيث من حيث ارتفاعات و امـاكن قطع الأثاث

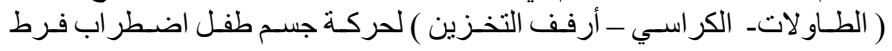

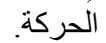

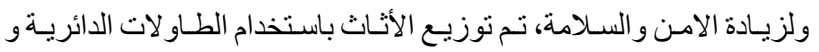

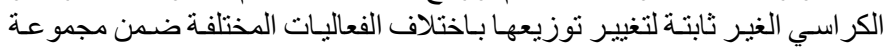

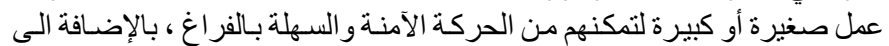

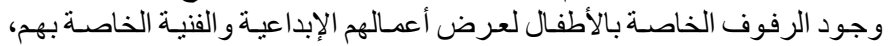
كذلك تو افر وحدات جلوس للمتخصصين بين مقاعد الاطفال.

3-9

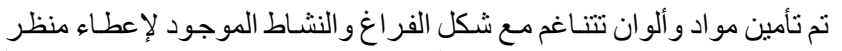

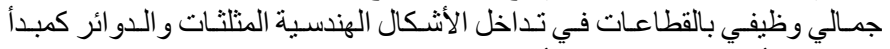

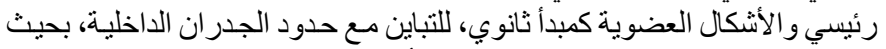

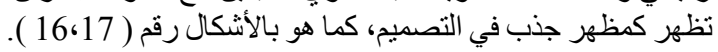

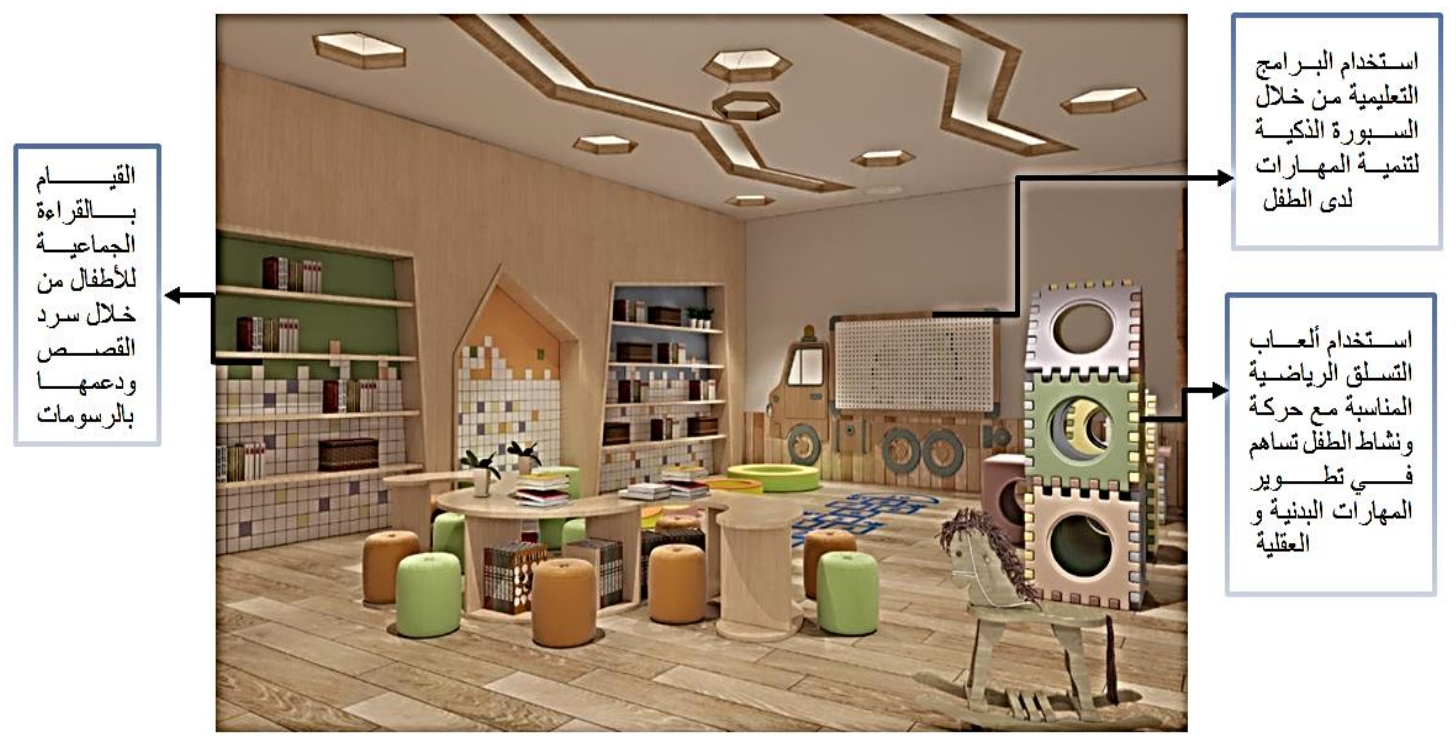

شكل رقم ( 18 ): يوضح توفير الأنشطة المختلفة بالقاعة التفاعلية المرجع: الباحثة 


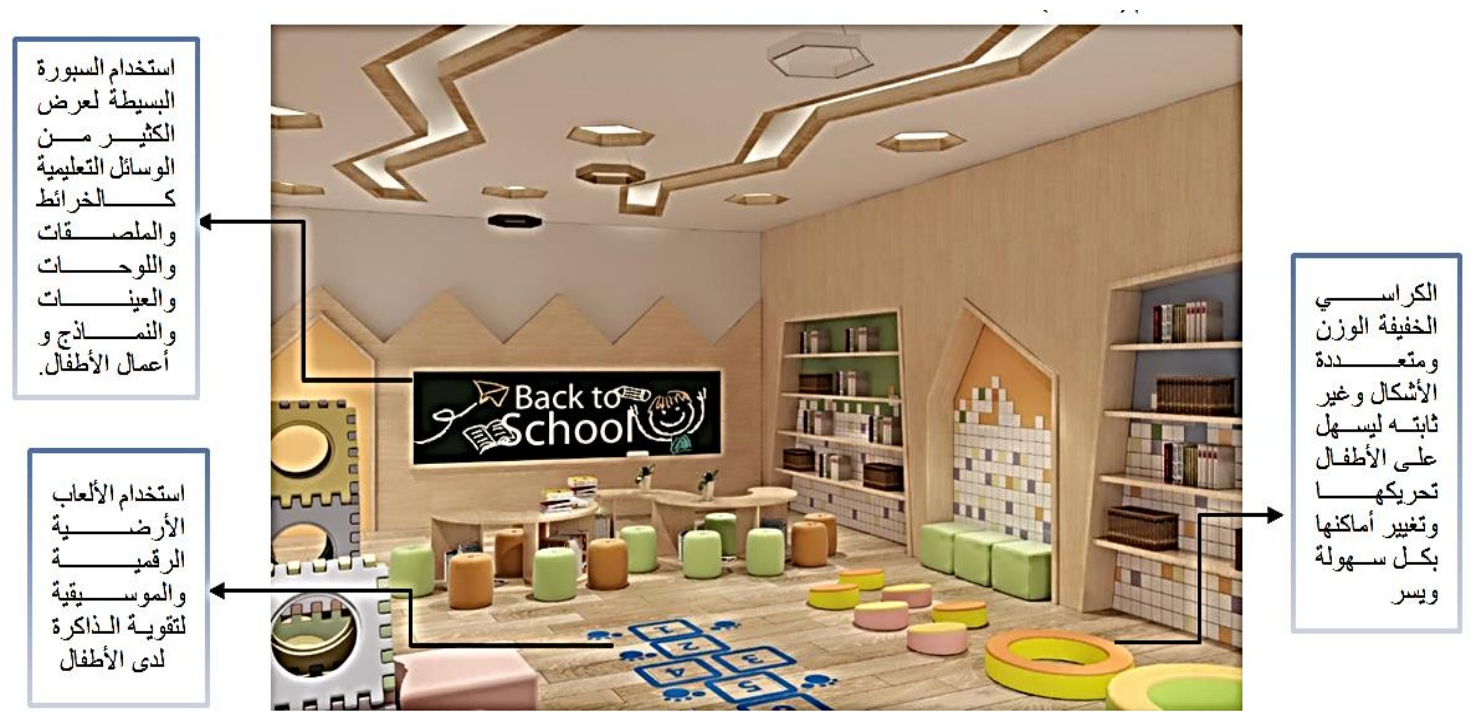

شكل رقم ( 19 ): يوضح التتوع في الاستعمالات و الاستخدامات في الأرضيات والجدران بداخل القاعة التفاعلية المرجع: الباحثة

الدف وسهولة التشكيل، مع تصميم تفريعات لوضع أرفف التخزين بها

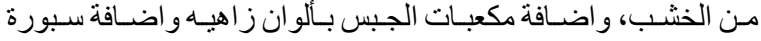

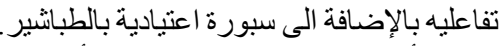

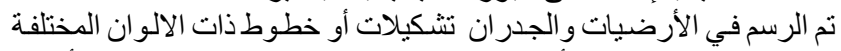

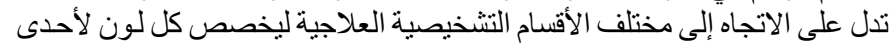

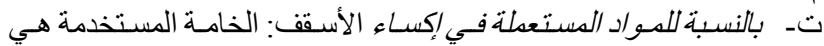

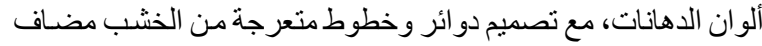

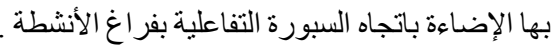

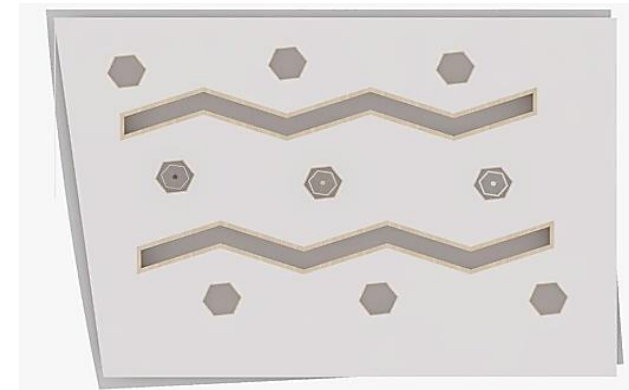

شكل رقم ( 21 ): يوضح المسقط الأفقي لسقف فر اغ القاعة التفاعلية للأنثطة

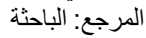

2-10 2-10 اعتبارات الأمن والسلامة:

تم تامين حركة المستخدمين دون خطر أو خوف على الى الصحة العامة والعاد وتقليل

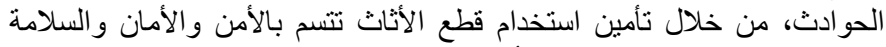

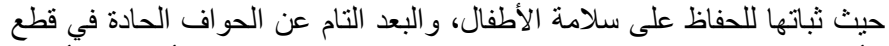

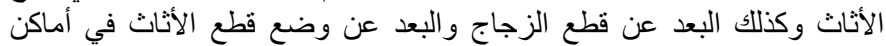

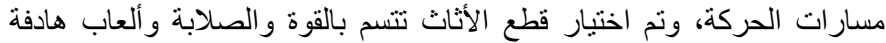
مطابقة لمعايير الأمن والسلامة، ومساحات ظل التاثل مناسبة وتتم صيانتها بشكل تم توفير الكراسي الخفيفة الوزن ليسهل على الأطفال تحريكها وتغيير أماكنها

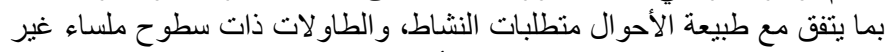

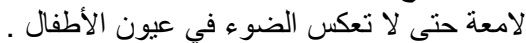

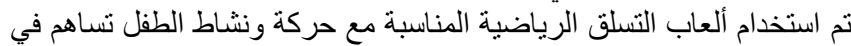

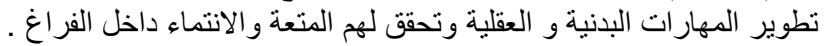

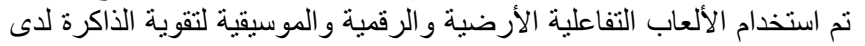

2-1-10 - 2-10 مسارات الحركة:

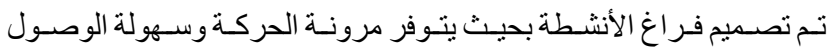

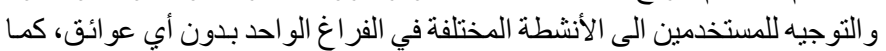

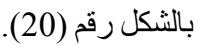

تمثل سهولة الحركة وتساعد على تكوين النشاطات التفاعلية الجماعية من خلال

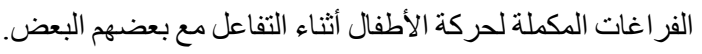

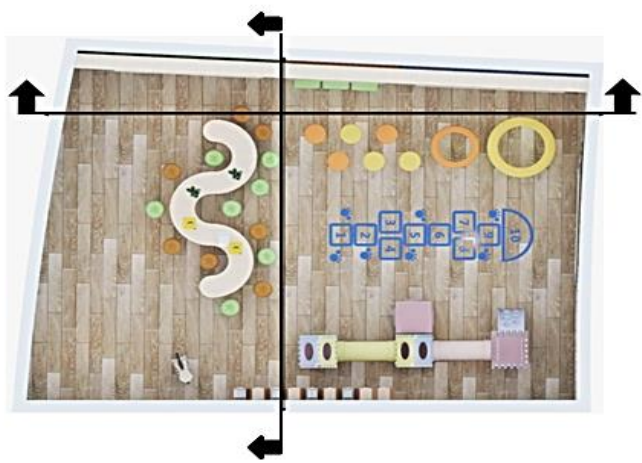

شكل رقم ( 20 ): : يوضح المسقط الأفقي لفراغ القاعة التفاعلية للانشطة

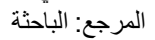

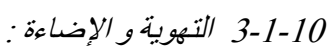

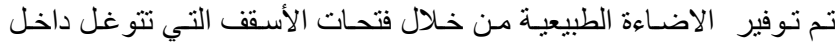

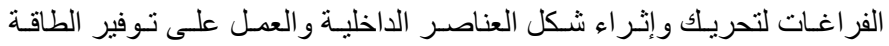

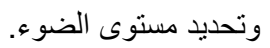

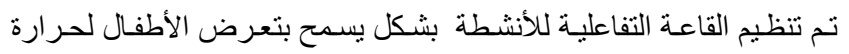

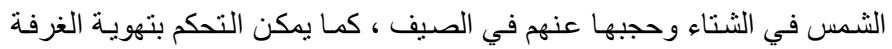

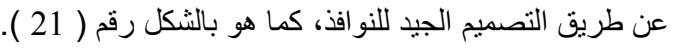

$$
\text { 4-1-10 مواد النهو (التشطيبات ) من حيث: }
$$

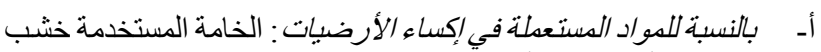

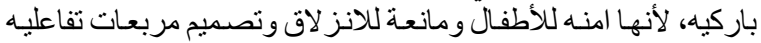
تعليميه للأطفال لاستغلال حر كتهم بطريقة تلعليميه.

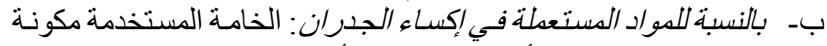

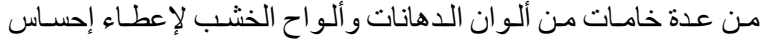




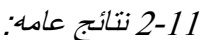

امكانية دمج التعليم والترفيه والابداع لفئة اطفال فرط الحركة والتي تساهم في علاجهم وتحسين حالاتهم.

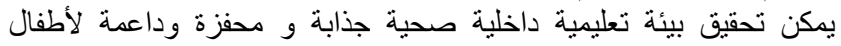

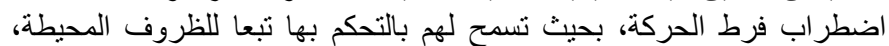

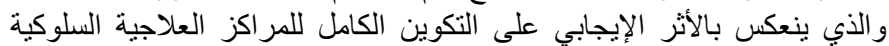

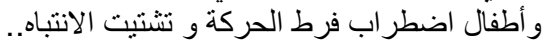

\section{2. التوصيات البحثية:}

1-12 توصيات للمصدم الداخلي و المهندس المعداري:

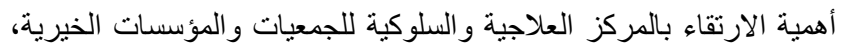

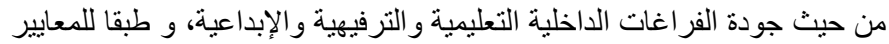

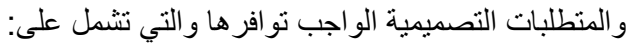

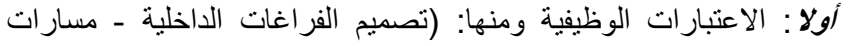

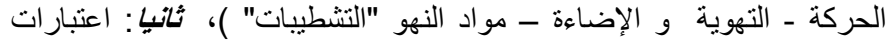

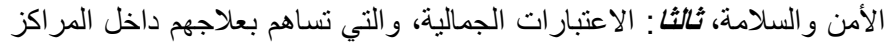

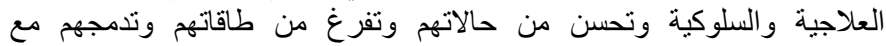

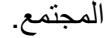

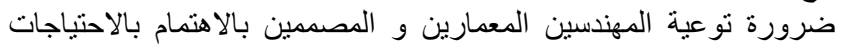
و المتطلبات التصميمة لذوي الاحتباجات الخاصنة، ومر اعاة التغير التيرات المستقبلية

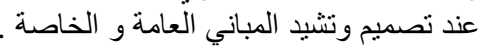

2-12 2- 2 توصيات عـامه

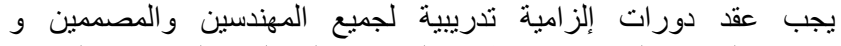

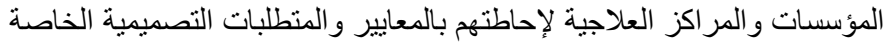

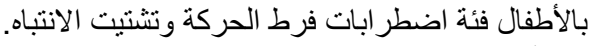

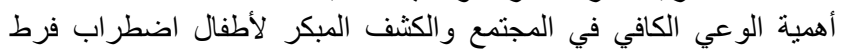
الحركة، وذللك لان العلاج المبكر يمنع من حدوث الكن ولكثير الكنير من المشكلات المستقبلية للطفل و أهله.

أهمية انشاء مؤسسات و جمعيات علمية متخصصة بالتصميم بجميع تفر عاته

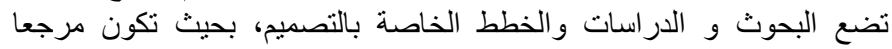

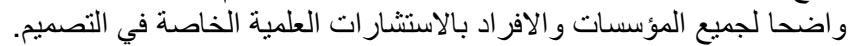

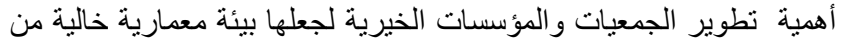
العو ائق من خلال اتباع المعايير و المتطلبات التصميمية للفر اغات الدئل الداخلية لأطفال

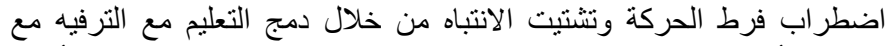

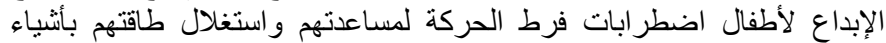
تستفاد منها في علاجهم و الاستجابة السريعة للتعلم و التعليم .

\section{قائمة المراجع}

[1] https://alqabas.com/article, , 20-4-2020

[2] Homidi, M., Obaidat, Y., \& Hamaidi, D. (2013). Prevalence of Attention Deficit and Hyperactivity Disorder among Primary School Students in Jeddah city, KSA. Life Science Journal, 285-280, (3)10.

[3] https://www.moh.gov.sa/HealthAwareness/EducationalContent/BabyHe alth/Pages/002.aspx, 16-4-2020

[4] https://adhd.org.sa/ar/article, 16-4-2020

[5] https://departments.moe.gov.sa/EducationAgency/RelatedDepartments/S PECIALEDUCATION/Pages/AttentionDeficit.aspx, 20-4-2020

[6] عبد الناصر تذكارات، " فعالية العلاج باللعب في خفض أعراض قلإنور الأنتباه وفرط النشاط

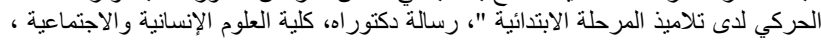

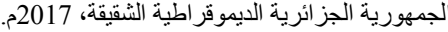

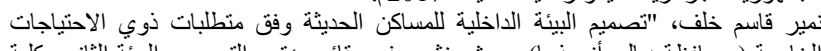

الخاصة ( محافظة ديالى أنموذجا)، بحث منشور في وقائع مؤتمر التصميم والبيئة الثاني، كلية الانية

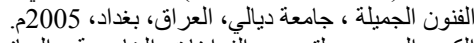

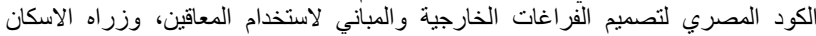

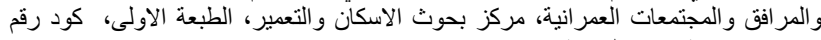
106، جمهورية مصر العربية ،2.2.2م.
تم استخدام السبورة الذكية ذات البر امج التعليمية و الترفيهية والإبداعية لتنمية

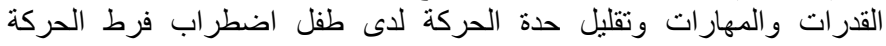
وتثتيت الانتباه .

3-10 3-10 الاعتبارات الجمالية :

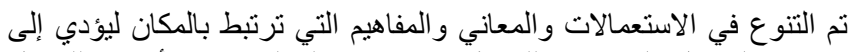

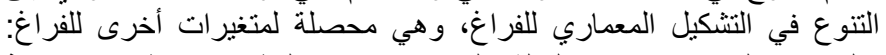

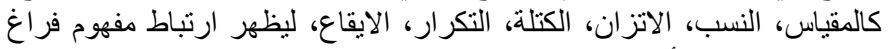

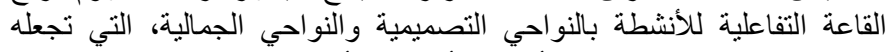

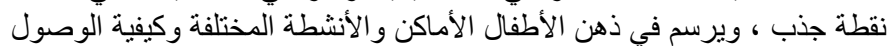

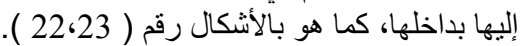

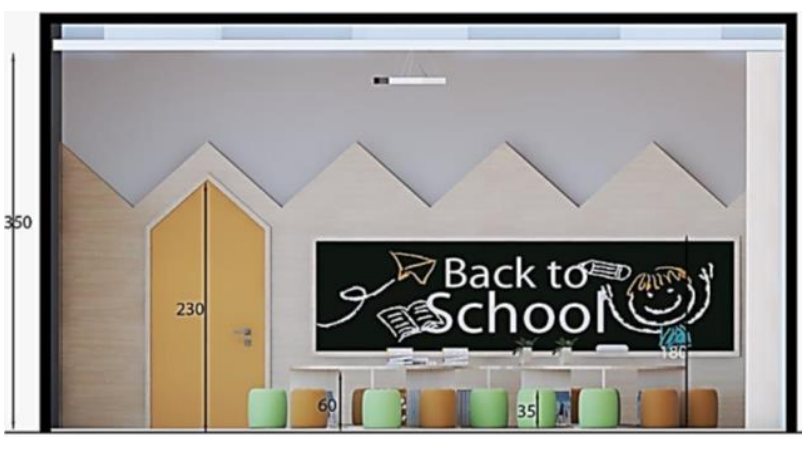

شكل رقم ( 22 ): يوضح التصميم: الداخلي بالقطاع الرأسي لفراغ الأنشطة

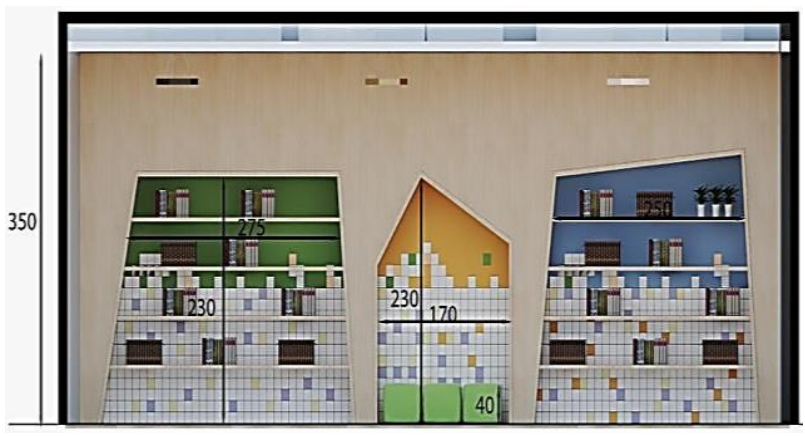

شكل رقم ( 23 ): يوضح التصميم الداخلي بالقطاع الافقي لفر اغ الأنشطة المرجع: الباحثة

\section{1. النتائج البحثية}

11 11 نتائج على حالة الدر/سة

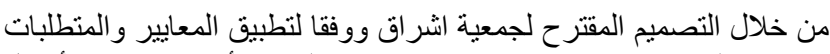

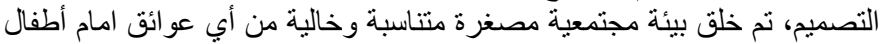
ذوي اضطر ابات الحركة ونتشتيت الانتباه.

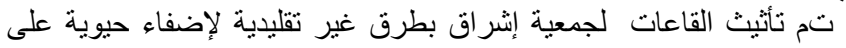

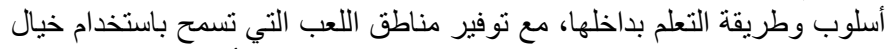

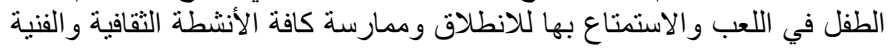

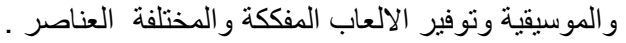

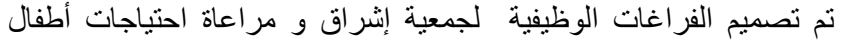

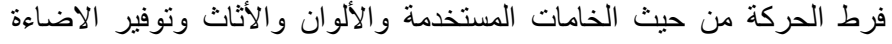
الطبيعية مع الإضاءة الصناعية.

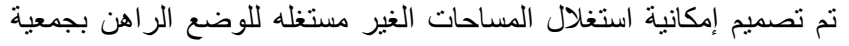

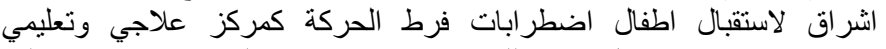

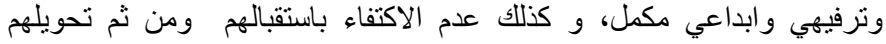

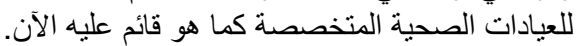


الذي يسببوه بتصرفاته الناتجة عن حركته الكثيرة دون الادر الك و الوعي بأنه طفل

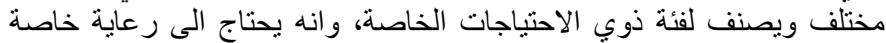

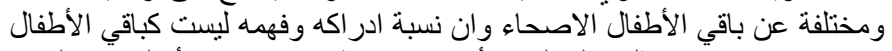

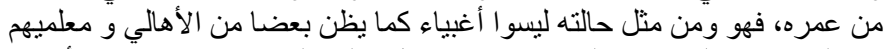

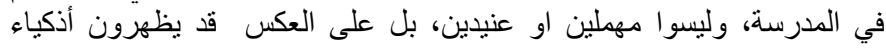

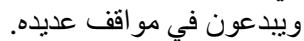

ومن هنا يجب توافر البيئة التصميمية الداخلية المناسبة في المر اكز العلاجية التبانية السلوكية والمتو افقة مع أنشطة اضطر ابات فرط الحركة وتثتنيت الانتباه لتلبية

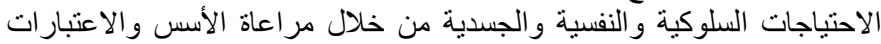

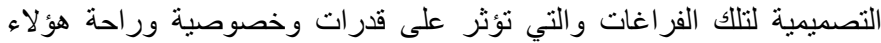

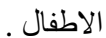

ويهدف البحث لاقتراح المعايير والأسس التصميمة الداخلية الناجحة

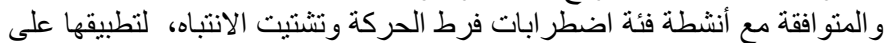

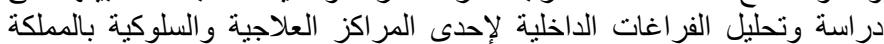

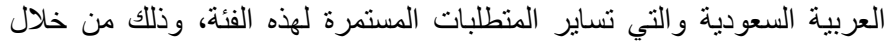

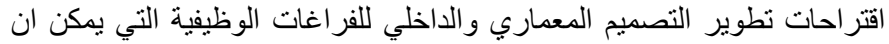

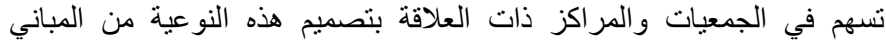

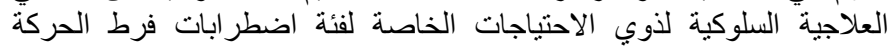

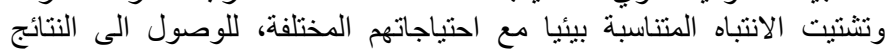

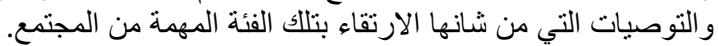

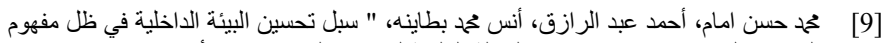

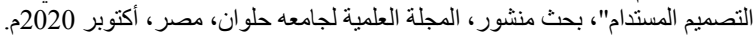

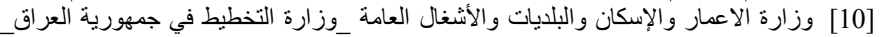
مدونة متطلبات البناء الخاص بذوي الاحتياجات الخاصةَ متطلبات بناء عر أقية، الطبعة الاولى، الألى

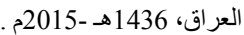

[11] منال السيد عبد الحميد، " المعايير التصميمية لدار المسنين - مشروع رعاية تطوير كبار

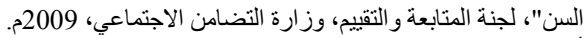

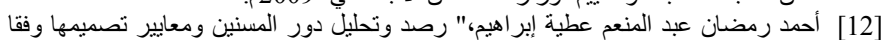
لر احة المقيمين بها باستخدام الثقنيات الحديثة"، رسالة ماجستير، كلية الهندسة، جامعة القاهرة، 2012م.

[13] ممدوح كمال احمد، حسام الدين محمد كر، " العلاقة بين الوظيفة والقيمة الجمالية - اقتراح

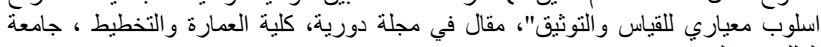
الملك عبد العزيز، 2002م. للئي

\section{Title Arabic:}

(تطوير المر اكز العلاجية السلوكية لخفض حدة النشاط الحركي الزائد

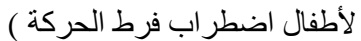

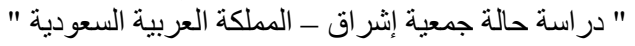

\section{Arabic Abstract:}

قد يرزق فئة من المجتمع بطفل ذو نشاط حركي زائد يختلف بها عن باقي

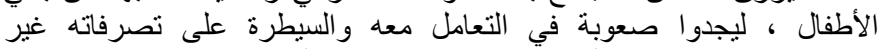

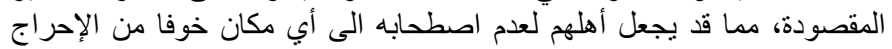

